Historikerkommissionen zur Legitimierung von Politik sind keine Erfindung der letzten Jahre. Eine der ersten war die 1956 ins Leben gerufene Kommission aus Historikern Polens und der DDR, die das deutsch-polnische Geschichtsbild im Zeichen des Sozialismus harmonisieren sollte - und dabei kläglich scheiterte, weil sich die polnischen Wissenschaftler weit weniger für politische Zwecke einspannen ließen als ihre ostdeutschen Kollegen. Stefan Guth von der Universität Bern beleuchtet diese stets prekären Verständigungsversuche und kontrastiert sie mit der Kooperation polnischer und westdeutscher Historiker, die auch in heiklen Fragen sehr viel rascher einen gemeinsamen Nenner fanden.

Stefan Guth

\title{
Erzwungene Verständigung?
}

Die Kommission der Historiker der DDR und der Volksrepublik Polen 1956-1990

„Ich kann mir ohne weiteres ein nationalistisches Deutschland im kommunistischen Mäntelchen vorstellen.“ (Zygmunt Wojciechowski, 1947) ${ }^{1}$

\section{Einleitung: Zwischen Erbfeindschaft und Völkerfreundschaft ${ }^{2}$}

Von 1956 bis 1990 unterhielten die Deutsche Demokratische Republik und die Volksrepublik Polen eine zwischenstaatliche Historikerkommission, deren Aufgabe in der Verständigung über die gemeinsame Vergangenheit von Deutschen und Polen bestand. Angesichts des zurückliegenden Krieges galt ihre Arbeit einem überaus diffizilen Gegenstand ${ }^{3}$; im Rahmen oktroyierter staatssozialistischer Systeme fand sie zudem unter ungünstigen Bedingungen statt. Bedacht mit dem Auftrag zur positiven Traditionsstiftung, hatte die Kommission ein weites

\footnotetext{
1 Zjazd niemcoznawczy w Poznaniu, 20-22 luty 1947r., [Der deutschlandkundliche Kongress in Posen, 20.-22. Februar 1947], 3 Bde., hier Bd. 1, Posen 1947 [maschinenschriftliches Manuskript, vervielfältigt], S. 122.

${ }^{2}$ Der vorliegende Aufsatz präsentiert Teilergebnisse einer breiter gefassten Dissertation, die im Mai 2009 bei Prof. Dr. Marina Cattaruzza am Historischen Institut der Universität Bern eingereicht worden ist und den deutsch-polnischen Historikerdialog von 1928-1976/1990 zum Gegenstand hat.

${ }^{3}$ Auch die Repräsentanten der Kommission suchten dies nicht zu verschleiern, so sollte etwa ein Dokumentenband über die deutsch-polnischen Beziehungen mit den Worten eingeleitet werden: „Es gab 1945 kaum zwei andere Völker, deren Beziehungen durch die Schuld der herrschenden Klassen Deutschlands so belastet waren wie das polnische und das deutsche Volk." Entwurf einer Einleitung für den Dokumentenband [über die Beziehungen zwischen der VR Polen und der DDR von 1949-1976], o.J. [1974?], in: Archiv der Berlin-Brandenburgischen Akademie der Wissenschaften (künftig: ABBAW), ZIG 710/2.
} 
Spannungsfeld zwischen alter „Erbfeindschaft“4 und neuer Völkerfreundschaft, geächtetem Nationalismus und angestrebtem Sozialismus zu überbrücken - ein Spannungsfeld, das etliche der beteiligten Historiker auch in ihrer Biographie verkörperten, sofern ihre wissenschaftliche Tätigkeit in die Zwischenkriegszeit zurückreichte $^{5}$. Für eine gründliche und mithin langwierige historiographische Aufarbeitung blieb indes kaum Zeit; die politische Agenda verlangte, dass die Vergangenheitsbewältigung nach den Regeln eines rigiden ideologischen Schematismus im Eiltempo erfolgte. Hinzu kam, dass die ostdeutsch-volkspolnische Historikerverständigung durch die fortgesetzte historiographische Auseinandersetzung zwischen der Bundesrepublik Deutschland und der Volksrepublik Polen nachhaltig konterkariert wurde ${ }^{6}$.

Folgt man der Selbstdarstellung der Kommission, so gingen diese Zusammenhänge freilich eine einfache Verbindung ein: Demnach hatte der Nationalismus der Zwischenkriegszeit die deutsch-polnische Verständigung hintertrieben (und hintertrieb sie in Westdeutschland noch immer), wohingegen der Sozialismus der Nachkriegsjahre eine Versöhnung ermöglichte, indem er nationale Gegensätze in internationaler Klassensolidarität aufhob ${ }^{7}$. Die Innenperspektive, wie sie

\footnotetext{
${ }^{4}$ Vgl. Zygmunt Wojciechowski, Polska - Niemcy. Dziesieć wieków zmagania [Polen - Deutschland. Zehn Jahrhunderte Kampf], Posen ${ }^{2} 1945$. Erstmals tritt die Denkfigur einer deutsch-slawischen Erbfeindschaft wohl bei František Palácky auf; vgl. Hermann Aubin, Die Deutschen in der Geschichte des Ostens, in: Geschichte in Wissenschaft und Unterricht 7 (1956), S. 512 545, hier S. 521. Ein weiterer prominenter Vertreter dieser Sichtweise in der polnischen Historiographie war Wacław Sobieski (1872-1935); vgl. Zdzisław Pietrzyk, Wacław Sobieski (18721935), in: Peter Brock/John D. Stanley/Piotr J. Wróbel (Hrsg.), Nation and History. Polish Historians from the Enlightenment to the Second World War, Toronto/Buffalo/London 2006, S. 246-259, hier S. 254.

${ }^{5}$ Dies gilt v. a. für die polnische Seite, wo eine weitaus größere Kontinuität der akademischen Fachelite bestand als in der DDR. Sowohl vor als auch nach 1945 hatten sich, um nur die wichtigsten zu nennen, folgende Forscher mit Deutschland befasst: Zygmunt Wojciechowski, Karol Górski, Tadeusz Manteuffel, Józef Kostrzewski, Kazimierz Tymieniecki und Władysław Konopczyński. Auch die volksrepublikanischen Deutschland-Experten Gerard Labuda und Bogusław Leśnodorski hatten bereits vor 1939 erste wissenschaftliche Erfahrungen gesammelt. In Deutschland fanden sich die in der Zwischenkriegszeit mit Osteuropa befassten Historiker nach 1945 größtenteils in der BRD zusammen - u. a. Hermann Aubin, Hans Rothfels, Theodor Schieder und Werner Conze. In der DDR wurden auf dem Feld der Osteuropa-Historiographie dagegen nur vergleichsweise wenige Karrieren aus der Vorkriegszeit fortgesetzt (Wilhelm Unverzagt, Eduard Winter); mehrheitlich wurde das Fach mit neuen Köpfen aufgebaut (FelixHeinrich Gentzen, Johannes Kalisch, Reinhold Jeske, Heinz Lemke, Eva Seeber), was den Vorteil geringerer Belastung, aber auch den Nachteil einer weitgehend fehlenden Forschungstradition mit sich brachte.

${ }^{6}$ So taten sich die polnischen Historiker oft schwer damit, sich nach der Gründung der DDR „vo[m] bisherigen integralem Verständnis der deutschen Frage“ abzuwenden und ein "gutes" von einem „schlechten“ Deutschland zu unterscheiden. Henryk Olszewski, Instytut Zachodni 1944-1994 [Das Westinstitut 1944-1994], in: Romuald Zwierzycki (Hrsg.), Instytut Zachodni 50 lat, Posen 1994, S. 5-70, hier S. 20.

${ }^{7}$ Siehe etwa das Vorwort von Helmut Bleiber in: DDR-Sektion der Kommission der Historiker der DDR und der Volksrepublik Polen (Hrsg.), 30 Jahre Kommission der Historiker der DDR und der Volksrepublik Polen. Eine Chronik, Berlin 1986.
} 
aus den Quellen hervortritt ${ }^{8}$, offenbart freilich, dass unter der Kruste verordneter Freundschaft erhebliche Gegensätze fortbestanden ${ }^{9}$.

Im Folgenden soll deshalb dargestellt werden, wie die deutsch-polnische Beziehungsgeschichte im volksdemokratischen Kontext fortgeschrieben wurde ${ }^{10}$. Dabei wird zu zeigen sein, dass dem historiographischen Paradigmenwechsel, weg von nationalen Gegensätzen und hin zu sozial-stratifikatorisch begründeten Solidaritäten, nur zweifelhafter Erfolg beschieden war. Die solchermaßen überspielten Altlasten der Vergangenheit ließen sich nicht dauerhaft aus dem deutsch-polnischen Diskurs verbannen; sie beschäftigten die Kommission immer wieder und polarisierten entlang der nationalen Scheidelinie. In mehr oder minder scharfer Abweichung vom nationalen Agnostizismus der historisch-materialistischen Meistererzählung entwickelten deutsche und polnische Historiker im Lauf der Jahre grundlegend verschiedene Erklärungsansätze der gemeinsamen Vergangenheit und erschlossen sich dabei auch ganz unterschiedliche Interpretationsspielräume.

Erbringen soll der vorliegende Aufsatz im Lichte der umrissenen Fragestellung zweierlei: zunächst einen Beitrag zur bisher wenig erforschten Geschichte der deutsch-polnischen Beziehungshistoriographie in der Nachkriegszeit ${ }^{11}$, sodann

\footnotetext{
8 Zur Tätigkeit der Kommission sind heute umfangreiche Bestände einsehbar, die sich im Archiv der Berlin-Brandenburgischen Akademie der Wissenschaften, im Bundesarchiv Berlin, dem Instytut Historii Polskiej Akademii Nauk, dem Archiwum Akt Nowych und dem Archiwum Ministerstwa Spraw Zagranicznych in Warschau konzentrieren und die gesamte Tätigkeitsspanne der Kommission abdecken.

${ }^{9}$ Hier ist Stelzig zu widersprechen, der - ohne Zugang zu den Akten der Kommission - davon ausgegangen war, dass Diskussionen „im eigentlichen Sinn“ kaum stattgefunden hätten, „da kontroverse Standpunkte höchst selten [...] aufeinanderstießen“. Günter Stelzig, Um ein gemeinsames Geschichtsbild? Die Zusammenarbeit der Historikerkommission der DDR mit ihren Fachkollegen aus der UdSSR, aus Polen und der Tschechoslowakei im Rahmen der bilateralen Historikerkommissionen (1955-1984), Erlangen 1987, S. 245. Hingegen war Rautenberg in einer knappen Darstellung schon zu Beginn der 1970er Jahre aufgefallen, dass „auf den gemeinsamen Tagungen deutsche und polnische Wissenschaftler durchaus geteilte Auffassungen vertreten“. Hans-Werner Rautenberg, Die deutsch-polnische Historikerkommission, in: Manfred Hellmann (Hrsg.), Osteuropa in der historischen Forschung der DDR, 2 Bde., hier Bd. 1, Düsseldorf 1972, S. 114-122, hier S. 114.

${ }_{10}$ Als allgemeiner Überblick zur Historiographie der deutsch-polnischen Beziehungen Klaus Zernack, Das Jahrtausend deutsch-polnischer Beziehungsgeschichte als Problemfeld und Forschungsaufgabe, in: Ders. (Hrsg.), Preussen - Deutschland - Polen. Aufsätze zur Geschichte der deutsch-polnischen Beziehungen, Berlin 1991, S. 3-42.

11 Der Forschungsstand zur Kommission und zum ostdeutsch-polnischen Historikerdialog präsentiert sich bisher sehr überschaubar. Eine knappe Übersicht lieferte erstmals Rautenberg, Historikerkommission, in: Hellmann (Hrsg.), Osteuropa, Bd. 1; die bisher einzige umfangreiche Studie zu den bilateralen Historikerkommissionen der DDR mit sozialistischen Staaten erschien 1987 noch ohne Einsicht in Archivquellen; vgl. Stelzig, Geschichtsbild. Eine erste quellengestützte Untersuchung hat jüngst Loose vorgelegt, der sich auf die Arbeitsbeziehungen der Berliner Humboldt-Universität zu polnischen Historikern konzentriert; vgl. Ingo Loose, Die Sprachlosigkeit der Ideologie: Polnisch-ostdeutsche geschichtswissenschaftliche Beziehungen 1950-1970, in: Zeitschrift für Geschichtswissenschaft 56/2 (2008), S. 935-955. Zwei gute Übersichtsbeiträge zur Entwicklung der Osteuropahistoriographie in der DDR, die am Rande auch
} 
eine vergleichende Perspektive auf die bisher sehr DDR-zentrisch behandelte Frage nach den Möglichkeiten und Grenzen „gebundener Geschichtswissenschaft" im Sozialismus ${ }^{12}$.

\section{Voraussetzungen und Anfänge}

Als die deutsch-polnische Historikerkommission 1956 ihre Arbeit aufnahm, blickten nicht nur die beiden Völker, sondern insbesondere auch ihre Historiker auf eine spannungsreiche Beziehungsgeschichte zurück $^{13}$. Hatten schon die Geschichtsschreiber des 19. Jahrhunderts Polen und Deutsche zunehmend als historische Kontrahenten geschildert, so verschärfte Versailles die historiographische Auseinandersetzung nach 1918 zum politischen Kampf, der in Deutschland um Revision, in Polen um Legitimation der neuen Grenze geführt wurde ${ }^{14}$. In den 1920er und -30er Jahren zogen Ostforschung in Deutschland und Westgedanke in Polen ${ }^{15}$ eine steigende Zahl von Historikern in den deutsch-polnischen Gelehrtenstreit $^{16}$, der vom Ausbruch des Zweiten Weltkrieges in den Schatten gestellt, aber keinesfalls beendet wurde. So ließen sich etliche deutsche Historiker auf die

die Beziehungen zu Polen streifen und eine Vorstellung von der Parteikontrolle über die wissenschaftliche Forschung vermitteln, bieten Alexander Fischer, Forschung und Lehre zur Geschichte Osteuropas in der sowjetischen Besatzungszone bzw. der Deutschen Demokratischen Republik (1945-1990), in: Erwin Oberländer (Hrsg.), Geschichte Osteuropas. Zur Entwicklung einer historischen Disziplin in Deutschland, Österreich und der Schweiz 1945-1990, Stuttgart 1992, S. 304-341, und Lutz-Dieter Behrendt, Die Osteuropahistoriographie in der DDR. Das Beispiel Leipzig, in: Dittmar Dahlmann (Hrsg.), Hundert Jahre Osteuropäische Geschichte. Vergangenheit, Gegenwart und Zukunft, Stuttgart 2005, S. 183-194.

${ }^{12}$ Einzig Górny hat bisher Vergleichslinien zwischen der Historiographie der DDR und jener der Volksrepublik Polen und der ČSSR gezogen, wobei er den Begriff des „Volks“ ins Zentrum stellte; vgl. Maciej Górny, Przede wszystkim ma być naród. Marksistowskie historiografie w Europie Środkowo-Wschodniej [An erster Stelle steht das Volk. Marxistische Historiographie in Mittelosteuropa], Warschau 2007. Den weit über die Historiographiegeschichte hinausgehenden Mangel an vergleichenden Sichtweisen auf die DDR-Geschichte beklagte Jürgen Kocka, Der Blick über den Tellerrand fehlt, in: Frankfurter Rundschau vom 22. 8. 2003.

${ }^{13}$ Konzis dargestellt bei Henryk Olszewski, Die deutsche Historiographie über Polen aus polnischer Sicht, in: Dahlmann (Hrsg.), Hundert Jahre Osteuropäische Geschichte, S. 281-292.

${ }^{14}$ Vgl. Stefan Guth, Between confrontation and conciliation. German-polish historiographical relations in the 1930s, in: Storia della Storiografia 47 (2005), S. 113-160.

15 Dabei handelte es sich um multidisziplinäre Forschungsrichtungen, die sich der wissenschaftlichen Untermauerung nationaler Ansprüche verschrieben; vgl. Jan Piskorski/Jörg Hackmann/ Rudolf Jaworski (Hrsg.), „Deutsche Ostforschung“ und „polnische Westforschung“ im Spannungsfeld von Wissenschaft und Politik. Disziplinen im Vergleich, Osnabrück/Posen 2002.

${ }_{16}$ Auf deutscher Seite u. a. Albert Brackmann (1871-1952), Hermann Aubin (1885-1969), Hans Rothfels (1891-1976), Theodor Oberländer (1905-1998), Theodor Schieder (19081984) und Werner Conze (1910-1986), in Polen Wacław Sobieski (1872-1935), Władysław Konopczyński (1880-1952), Józef Kostrzewski (1885-1969), Kazimierz Tymieniecki (18871968), Teodor Tyc (1896-1927), Marian Zygmunt Jedlicki (1899-1954), Zygmunt Wojciechowski (1900-1955) und Karol Górski (1903-1988). 
Expansionspläne der Nationalsozialisten ein ${ }^{17}$, während Teile der polnischen Historikerschaft, obgleich härtesten Verfolgungen ausgesetzt, im Untergrund an der historischen Begründung eines polnischen Nachkriegsstaates arbeiteten, der auf Kosten Deutschlands weit nach Westen ausgreifen sollte ${ }^{18}$. Als 1945 die alliierte Grenzziehung entlang Oder und Neiße solche Vorstellungen (unter dem Vorbehalt einer abschließenden Friedensregelung) Realität werden ließ, wurde sie einmal mehr mit historischen Argumenten angefochten bzw. gerechtfertigt. Gleichzeitig komplizierte die Bildung zweier deutscher Staaten den vormals bilateralen Schlagabtausch zur Dreieckskonstellation. Im neuen sozialistischen Polen verhalf das Bedürfnis nach schlagkräftiger Verteidigung der neuen Grenze dem Westgedanken ungeachtet seiner bürgerlich-katholisch gesinnten Trägerschaft zu einer schnellen Wiederbelebung ${ }^{19}$, und in Westdeutschland gelang es den Exponenten der Ostforschung, ihre revisionistischen Forschungsprogramme aus der Zwischenkriegszeit im Zeichen des Kalten Krieges zu aktualisieren ${ }^{20}$.

Im Schatten dieser wiederbelebten Konfrontation nahm sich die historiographische Annäherung zwischen der DDR und der Volksrepublik Polen zunächst bescheiden aus. Betrieben wurde sie von einzelnen Historikern, die beiderseits der Grenze als Vorreiter einer „progressiven“ Geschichtsauffassung auftraten und im diskursiven Prokrustesbett des Historischen Materialismus der sozialistischen Völkerverständigung das Wort redeten. So verurteilten ostdeutsche Geschichtsforscher wie Felix-Heinrich Gentzen und H. Baumann in polnischen Fachzeitschriften die antipolnische Stoßrichtung der nichtsozialistischen deutschen Historio-

17 Als Übersicht vgl. Winfried Schulze/Otto Gerhard Oexle (Hrsg.), Deutsche Historiker im Nationalsozialismus, Frankfurt a. M. ${ }^{4} 2000$, insbesondere die Beiträge von Götz Aly, Wolfgang J. Mommsen, Ingo Haar, Michael Fahlbusch und Hans Mommsen.

${ }_{18}$ Wrzesiński bezeichnet das Konzept einer vorgeschobenen polnischen Westgrenze als integrierende Leitidee, die wesentlich dazu beitrug, den heterogenen polnischen Widerstand im Zweiten Weltkrieg zu einigen; vgl. Woiciech Wrzesiński, Kresy czy pogranicze? Problem ziem zachodnich i północnych w polskiej myśli politycznej XIX i XX w. [Kresy oder Grenzland? Das Problem der West- und Nordgebiete im polnischen politischen Denken des XIX. und XX. Jh.], in: Ders. (Hrsg.), Miȩdzy Polską etniczna̧ a historyczna̧, Breslau/Warschau/Krakau 1988, S. 119-165, hier S. 165. Zygmunt Wojciechowski fasste für einen künftigen Friedensschluss mit dem besiegten Deutschland bereits 1941 eine polnische Westgrenze an Oder und Neiße ins Auge; vgl. Markus Krzoska, Für ein Polen an Oder und Ostsee. Zygmunt Wojciechowski (1900-1955) als Historiker und Publizist, Osnabrück 2003, S. 311.

19 Besonders augenfällig wurde diese Entwicklung mit der Gründung des Posener Instytut Zachodni (Westinstitut) unter Leitung von Zygmunt Wojciechowski.

${ }^{20}$ Zunächst versammelten sich die überlebenden Ostforscher im Göttinger Arbeitskreis, 1950 kam es dann auf Betreiben von Hermann Aubin zur Gründung des Herder-Instituts in Marburg, das sich in der Folge federführend der historiographisch-politischen Auseinandersetzung mit Polen widmete. Zur Restauration der Ostforschung in der Bundesrepublik Deutschland vgl. Corinna Unger, Ostforschung in Westdeutschland. Die Erforschung des europäischen Ostens und die Deutsche Forschungsgemeinschaft 1945-1975, Stuttgart 2007. Die Geschichte des Herder-Instituts wurde noch nicht geschrieben; erste Ansätze finden sich bei Eduard Mühle, „Ostforschung“, Ostmitteleuropaforschung und das Marburger Herder-Institut. Anmerkungen zu einem komplexen Beziehungsgeflecht, in: Krzystof Ruchniewicz (Hrsg.), Dzieje Śląska w świetle badań młodych historyków z Polski, Czech i Niemiec, Breslau 2000, S. 276-292. 
graphie $^{21}$, und 1950 propagierten polnische Historiker in Breslau unter politischem Druck eine Neubewertung der deutsch-polnischen Beziehungsgeschichte auf sozialistischer Basis. Man habe nun, so Ewa Maleczyńska, „eine gemeinsame Sprache [...] mit der fortschrittlichen deutschen Wissenschaft" gefunden ${ }^{22}$. Drei Jahre später schlug ein ranghoher polnischer Wissenschaftsfunktionär die Bildung einer gemeinsamen Historikerkommission vor ${ }^{23}$. Im Oktober 1954 kam es zu einer ersten, über Einzelkontakte hinausgehenden Begegnung, als ostdeutsche Historiker auf Einladung der Polnischen Akademie der Wissenschaften an einer Tagung zum „500. Jahrestag der Rückkehr Pommerns nach Polen“ teilnahmen $^{24}$. Bereits aus der Themenstellung wird ersichtlich, dass das polnische Interesse an bilateralen Kontakten sich zunächst darauf beschränkte, ostdeutsche Historiker für die Legitimierung des status quo post 1945 einzuspannen. Pflichtschuldig betonte Gentzen denn auch den „urpolnischen Charakter“ Pommerns ${ }^{25}$. Im Anschluss an die Tagung erörterten deutsche und polnische Historiker mögliche Gemeinschaftsprojekte ${ }^{26}$, die im Juli 1955 in den Politbürobeschluss „Über die Verbesserung der Forschung und Lehre in der Geschichtswissenschaft der Deutschen Demokratischen Republik“ eingingen. Erforscht werden sollten demnach die „Freundschaft zwischen den deutschen Demokraten und den polnischen Revolutionären Ende des XVIII. und in der ersten Hälfte des XIX. Jahrhunderts, [sowie] der gemeinsamen Kämpfe der deutschen und polnischen Arbeiterklasse vor dem ersten Weltkrieg und in der Zeit der Weimarer Republik

\footnotetext{
${ }^{21}$ Vgl. Felix-Heinrich Gentzen, „Ostforschung“ zachodnio-niemieckich historyków [Die "Ostforschung" der westdeutschen Historiker], in: Przegląd Zachodni 12/1 (1956), S. 291-300. Den gesellschaftlichen Rahmen für die deutsch-polnische Verständigung sollte die 1948 in Berlin gegründete Hellmut-von-Gerlach-Gesellschaft für deutsch-polnische Freundschaft bilden, die ihre Tätigkeit in der DDR allerdings bereits 1953 wieder einstellte, nachdem sie in der Gesellschaft für kulturelle Verbindungen mit dem Ausland aufgegangen war; vgl. Stelzig, Geschichtsbild, S. 238 f.

${ }^{22}$ Die Protokolle dieser Konferenz wurden 1963 im Auftrag des Herder-Forschungsrates nahezu ungekürzt in deutscher Übersetzung herausgegeben: Herbert Ludat (Hrsg.), Polen und Deutschland. Wissenschaftliche Konferenz polnischer Historiker über die polnisch-deutschen Beziehungen in der Vergangenheit, Köln/Graz 1963, Zitat S. 52.

${ }^{23}$ Es handelte sich um Bronisław Krauze vom Institut für wissenschaftliche Kaderausbildung beim ZK der Polnischen Vereinigten Arbeiterpartei. Er schlug eine vertiefte Zusammenarbeit zwischen seinem Institut und dem Institut für Gesellschaftswissenschaften beim ZK der SED vor. Karl Obermann, Bericht über Besprechungen mit polnischen Historikern in Warszawa, Krakow und Wrocław, 21. 12. 1953, in: Archiv der Humboldt-Universität zu Berlin (künftig: AHUB), Philosophische Fakultät nach 1945, 76.

${ }^{24}$ Stelzig, Geschichtsbild, S. 239.

${ }^{25}$ So die Polnische Presseagentur PAP und die Parteizeitung Trybuna Ludu vom 25.10. 1954. Die Rückendeckung ostdeutscher Historiker für polnische Territorialinteressen wurde in der Bundesrepublik misstrauisch verfolgt. Siehe Presse- und Informationsdienst der Bundesregierung, Polnische Wissenschaft über Pommern, Bonn, Nr. 179/54 vom 18. 11. 1954, in: Bundesarchiv (künftig: BA) Koblenz, B 106/1161.

${ }^{26}$ Im März 1955 kam es zu einem weiteren bilateralen Treffen. Von deutscher Seite nahmen Gerhart Schilfert, K. Obermann und Felix Heinrich Gentzen teil, die polnische Seite war durch Bronisław Krauze, Ewa Maleczyńska, Kazimierz Popiołek, Henryk Zieliński, Władysław Długoborski und Bogusław Leśnodorski vertreten; vgl. Stelzig, Geschichtsbild, S. 239 f.
} 
gegen die Kriegs- und nationale Unterdrückungspolitik der deutschen und polnischen Imperialisten und Monopolisten“. Bei alledem gelte es, den „Fälschungen“ der Ostforschung entgegenzutreten ${ }^{27}$.

Der geplanten Zusammenarbeit stand allerdings die grundsätzliche Deutschland-Skepsis vieler polnischer Historiker entgegen - institutionell verkörpert im Posener Westinstitut (Instytut Zachodni), dessen pauschal antideutsche Positionen durch die Existenz eines sozialistischen deutschen Staates keine nennenswerte Erschütterung erfahren hatten ${ }^{28}$. Im Mai 1956 statteten Felix-Heinrich Gentzen und Gerhard Schilfert dem Institut deshalb einen Besuch $\mathrm{ab}^{29}$ und rangen den Verantwortlichen die Zusage ab, zukünftig „Polens Bevölkerung die ungeheure Bedeutung der Entstehung der DDR auf[zu]zeigen“30. Erstmals scheinen bei dieser Gelegenheit die ostdeutschen Beweggründe für die bilaterale Zusammenarbeit auf, die darauf abzielten, von den Polen die moralische Anerkennung einer positiven, von der DDR fortgeführten Tradition der deutschen Geschichte zu erlangen.

Damit war der Boden für die Gründung der Kommission der Historiker der Deutschen Demokratischen Republik und der Volksrepublik Polen (DPHK) bereitet, die am 7. Mai 1956 in Warschau erfolgte und der auch ein führender Vertreter des Posener Westinstituts (Gerard Labuda) beiwohnte ${ }^{31}$. Aufgabe der DPHK sollte es sein, „die freundschaftlichen Beziehungen der Völker beider Länder“ $\mathrm{zu}$ fördern ${ }^{32}$. Zu diesem Zweck verständigte man sich darauf, zunächst eine wechselseitige Harmonisierung der Schulbücher herbeizuführen ${ }^{33}$, um dann in einem zweiten Schritt auch die wissenschaftliche Forschung zu Themen von beiderseitigem Interesse gemeinsam anzugehen ${ }^{34}$. Mit solchen Zielsetzungen fügte sich die DPHK scheinbar nahtlos in den internationalen Kontext ähnlicher Kom-

\footnotetext{
${ }^{27}$ Die Verbesserung der Forschung und Lehre in der Geschichtswissenschaft der Deutschen Demokratischen Republik [Beschluss des Zentralkomitees der Sozialistischen Einheitspartei Deutschlands], in: Zeitschrift für Geschichtswissenschaft 3 (1955), S. 507-527, hier S. 518.

${ }^{28}$ Institutsdirektor Wojciechowski hatte sich bereits 1949 dem politischen Druck gebeugt und in einem Leitartikel die Notwendigkeit anerkannt, zwischen der BRD und der DDR zu unterscheiden; vgl. Zygmunt Wojciechowski, Distinguendum est, in: Przegląd Zachodni 5/2 (1949), S. 185-188. Dieses Lippenbekenntnis fand aber nur sehr verhaltenen Niederschlag in der wissenschaftlich-propagandistischen Arbeit des Instituts.

${ }^{29}$ Vgl. Stelzig, Geschichtsbild, S. 241; Przeglasd Zachodni 12 (1956), S. 431.

${ }^{30}$ Przegląd Zachodni 12 (1956), S. 225-228, zit. nach Rudolf Neumann, Polens Westarbeit. Die polnischen Kultur- und Bildungseinrichtungen in den deutschen Ostgebieten, Bremen 1966, S. 41 .

31 Vgl. Stelzig, Geschichtsbild, S. 241 f. Formale Grundlage der Kommissionsgründung war der Warschauer Vertrag über Freundschaft, Zusammenarbeit und gegenseitigen Beistand vom 14.5. 1955.

${ }^{32}$ Heinrich Scheel, Gründungstagung der deutsch-polnischen Historikerkommission, in: Zeitschrift für Geschichtswissenschaft 4/2 (1956), S. 805 f., hier S. 806.

${ }^{33}$ Kuczyński/Leśnodorski, Schlussprotokoll der 1. Tagung der deutsch-polnischen Historikerkommission [7.-11.3. 1956 in Warschau], 11.3. 1956, in: ABBAW, ZIG 555. Dieser Anspruch wurde allerdings nie umfassend verwirklicht.

${ }^{34}$ Geplant wurden vor allem gemeinschaftliche Darstellungen und Quellensammlungen zu beziehungsgeschichtlichen Fragen, u. a. zur deutsch-polnischen Freundschaft, zur Novemberre-
} 
missionen, die es sich nach den beiden Weltkriegen zur Aufgabe gemacht hatten, die nationale Engführung der Geschichtsschreibung im Interesse der Völkerverständigung zu überwinden ${ }^{35}$. Angesichts solcher Vorbilder glaubte man sich auch verpflichtet, die Entstehung der Kommission akademisch-zivilgesellschaftlicher Initiative zuzuschreiben - „persönliche Kontakte“, so Helmut Bleiber rückblickend, hätten die „wesentliche[n] Voraussetzungen“ zur Gründung einer bilateralen Historikerkommission geschaffen ${ }^{36}$. Hier sind Zweifel angebracht: Im Gegensatz zu den westeuropäischen Historikerkommissionen, die in der Regel tatsächlich auf die Initiative Einzelner zurückgingen und erst allmählich von der UNESCO koordiniert wurden ${ }^{37}$, lassen die Mitte der fünfziger Jahre in schneller Folge gegründeten Historikerkommissionen im sowjetischen Einflussbereich eine aus Moskau gesteuerte Initiative zur Vernetzung der Nationalhistoriographien im sowjetischen Einflussbereich vermuten ${ }^{38}$. Dabei stand anfangs wohl nicht so sehr die Gleichschaltung der nationalen Historiographien im Vordergrund, sondern im Gegenteil die kontrollierte Entfesselung lange aufgeschobener Diskussionen über beziehungsgeschichtliche Streitfragen, die die sozialistische Eintracht unter der Oberfläche des offiziellen Freundschaftsdiskurses empfindlich störten ${ }^{39}$. Im

volution, zur Zeit der sächsischen Könige in Polen, zum Ostmarkenverein und zu den „monopolistischen Verbindungen in der schlesischen Industrie“. Ebenda.

${ }_{35}$ In der Forschung hat die Tätigkeit dieser Kommissionen bisher erstaunlich wenig Aufmerksamkeit gefunden. Einen ersten Gesamtüberblick bieten Marina Cattaruzza/Sacha Zala, Negotiated History? Bilateral historical commissions in twentieth-century Europe, in: Harriet Jones/ Kjell Östberg/Nico Randeraad (Hrsg.), Contemporary history on Trial, Manchester 2006, S. 123-143.

${ }^{36}$ Bleiber, Vorwort, in: 30 Jahre, S. 1. Diese Selbstdarstellung entspricht der konstatierten Neigung der DDR-Historiographie, sich nach außen zur „Normalwissenschaft“ zu stilisieren; vgl. Martin Sabrow, Die DDR-Geschichtswissenschaft als „Meta-Erzählung“, in: Ders. (Hrsg.), Verwaltete Vergangenheit. Geschichtskultur und Herrschaftslegitimation in der DDR, Leipzig 1997, S. 19-34, hier S. 23; ders, Beherrschte Normalwissenschaft. Überlegungen zum Charakter der DDR-Historiographie, in: Geschichte und Gesellschaft 24 (1998), S. 412-445.

${ }^{37}$ Vgl. Cattaruzza/Zala, Bilateral historical commissions, in: Jones/Östberg/Randeraad (Hrsg.), Contemporary history on Trial.

${ }^{38}$ Die Gründung der deutsch-tschechischen Kommission erfolgte 1955, jene der deutsch-ungarischen 1961. Die polnischen Historiker unterhielten ihrerseits bilaterale Kontakte in mehrere Nachbarstaaten. Ein zentraler „Gründungsbefehl“ aus Moskau lässt sich freilich weder in den deutschen noch in den polnischen Akten finden, ebenso wenig wie eine damit einhergehende verbindliche Aufgabenstellung. Auch Stelzig, Geschichtsbild, S. 242, bleibt den Beleg für seine Aussage schuldig, die DPHK sei im Zuge einer „von der UdSSR gewünschte Annäherung zwischen Polen und der DDR" entstanden.

${ }^{39}$ Dafür spricht der Gründungszeitpunkt im Umfeld des Tauwetters mit seiner gelockerten Diskussionskultur, die den Historikern anfänglich auch aktiv signalisiert wurde. Nur einen Monat nach Chruščevs Kritik an Stalin auf dem XX. Parteitag der KPdSU im Februar 1956 rief ein ungezeichneter Grundsatzartikel in Voprosy Instorii die sowjetischen Historiker zu quellennaher und faktengetreuer Arbeit auf und ermunterte sie, nicht erst auf „Anweisungen“ und „Direktivartikel“ zu warten. Georg G. Iggers/Wilhelm Schulz, Geschichtswissenschaft, in: Klaus D. Kernig (Hrsg.), Sowjetsystem und demokratische Gesellschaft. Eine vergleichende Enzyklopädie, Bd. 2, Freiburg/Basel/Wien 1968, S. 914-959, hier S. 935. Siehe auch Martin Sabrow, Das Diktat des Konsenses. Geschichtswissenschaft in der DDR 1949-1969, München 2001, S. 75. 
Anschluss an die poststalinistischen Unruhen in Polen und Ungarn wuchs indes schon bald wieder die Furcht vor den unberechenbaren Folgen einer wissenschaftlichen Liberalisierung ${ }^{40}$; nun wurden die Kommissionen unter zunehmender sowjetischer Beteiligung linientreu ausgerichtet ${ }^{41}$. Im Zusammenhang damit gewann auch das ursprüngliche Aussöhnungsanliegen einen seltsam changierenden Zuschnitt: Bisweilen wurden Verständigung und Aussöhnung - wie in den westlichen Kommissionen - als erstrebtes Ziel betrachtet und entsprechender Diskussionsbedarf vage anerkannt, bisweilen wurden sie unter Verweis auf die entspannende Wirkung internationaler Klassensolidarität als bereits gegebene Voraussetzung der Kommissionsarbeit angenommen, die nur noch entsprechend zu zelebrieren war - wobei letztere Option insbesondere das öffentliche Auftreten der Kommissionen prägte. Im Zeichen dieser verordneten Eintracht dienten die bilateralen Historikerkommissionen denn auch der Selbstdarstellung des sozialistischen Lagers nicht nur vor den eigenen Bürgern, sondern auch über die Blockgrenzen hinweg ${ }^{42}$.

Es war in diesem Zusammenhang wohl kein Zufall, dass die Gründung der ostdeutsch-polnischen Kommission just zu jenem Zeitpunkt erfolgte, als auch die bundesdeutschen Historiker erste Kontakte zu polnischen Kollegen knüpften. Werner Markert hatte 1956 in Tübingen erstmals seit Kriegsende bundesdeutsche und exilpolnische Historiker zum Gespräch über die gemeinsame Beziehungsgeschichte zusammengebracht, während Enno Meyer im selben Jahr ein vielbeachtetes Thesenpapier zu diesem Gegenstand vorlegte und damit auch bei volkspolnischen Historikern auf lebhafte Resonanz stie $\beta^{43}$. Nach sozialistischem Verständnis konnte es indes nicht angehen, dass eine historiographische Verständigung

\footnotetext{
${ }^{40}$ Beschluss des ZK vom März 1957, der die kurz zuvor erfolgten Liberalisierungssignale in den Voprosy Istorii als verfehlt kritisierte und scharfe administrative Maßnahmen gegen deren Redaktion nach sich zog. Im Juniheft der Zeitschrift wurde ein entsprechender Hinweis publiziert und damit die Tradition der Direktivartikel wieder aufgenommen; vgl. Iggers/Schulz, Geschichtswissenschaft, in: Kernig (Hrsg.), Sowjetsystem und demokratische Gesellschaft, S. 935.

41 Bezeichnend dafür scheint, dass das bisher dezentrale Beziehungsnetz durch die Gründung bilateraler Kommissionen mit sowjetischer Beteiligung jetzt einen Knotenpunkt in Moskau erhielt. Symptomatisch dafür war 1957 die Gründung der ostdeutsch-sowjetischen Kommission, die sich bereits auf ihrer konstituierenden Sitzung demonstrativ zur Orthodoxie bekannte; vgl. Stelzig, Geschichtsbild, S. 83; Sabrow, Diktat, S. 80. Es folgten - mit einiger Verspätung - bilaterale sowjetische Kommissionen mit Ungarn (1968) und Polen (1971).

${ }^{42}$ In diesen Deutungsrahmen passt auch das sowjetische Bestreben, Kontakte zu den Historikern westlicher Staaten - allen voran Italiens und Frankreichs - aufzunehmen.

${ }^{43}$ Vgl. Enno Meyer, Deutsch-polnische Schulbuchgespräche. Ein Zwischenbericht zu den gegenwärtigen deutsch-polnischen Schulbuchkonferenzen der beiderseitigen Unesco-Kommission, in: Geschichte in Wissenschaft und Unterricht 24 (1973), S. 35-43, hier S. 37; Krzystof Ruchniewicz, Zögernde Annäherung. Der Beginn des wissenschaftlichen Dialogs zwischen polnischen und deutschen Historikern in der Nachkriegszeit, in: Jahrbuch des deutschen PolenInstituts Darmstadt 11 (2000), S. 23-54, hier S. 26-41; Rafał Stobiecki, Klio na wygnaniu, Z dziejów polskiej historiografii na uchodźstwie w Wielkiej Brytanii po 1945 r. [Clio im Exil. Aus der Geschichte der polnischen Historiographie im Exil in Großbritannien nach 1945], Posen 2005, S. 139-145.
} 
zwischen polnischen und westdeutschen Historikern - letztere aus DDR-Perspektive uneinsichtige Erben der Ostforscher - eher gelang als zwischen zwei sozialistischen Schwesterhistoriographien. Es mochte daher aus Ostberliner Perspektive beruhigen, dass diese Annäherungsversuche aus blockpolitischen Gründen zunächst ohne Folgen blieben.

\section{Gegensätzliche Partner}

Freilich ließ sich auch die Verständigung zwischen ostdeutschen und polnischen Historikern mühevoll an. Schon in der Beurteilung der Meyerschen Thesen war man sich uneins - die ostdeutschen Historiker lehnten sie rundweg ab, während auf polnischer Seite nicht nur Exilhistoriker, sondern auch volkspolnische Fachvertreter Interesse zeigten und sich zu weiteren Gesprächen bereit erklärten ${ }^{44}$. Schwerer wog indes, dass zwischen Ostdeutschen und Volkspolen auch in der Schulbuchfrage keine Annäherung herbeigeführt werden konnte. Zwar hatte die zweite Sitzung der DPHK im November 1956 diese Frage zum zentralen Gegenstand, doch blieb eine Einigung in weiter Ferne. Das Protokoll musste sich schließlich damit begnügen, unüberwindbare Gegensätze notdürftig zu kaschieren:

„Die Aussprache über die Lehrbucharbeiten in der DDR und in der Volksrepublik Polen ergab völlige Übereinstimmung in dem wichtigen Punkt, eine Unifizierung der Auffassungen abzulehnen. Nicht immer war das, was für das deutsche Volk fortschrittlich war, ebenso fortschrittlich für das polnische Volk. Die Einheitlichkeit der Auffassung darf nicht darin bestehen, zu einer gleichmäßigen Behandlung gemeinsamer Probleme in beiden Ländern in beiden Lehrbüchern kommen zu wollen; die Einheitlichkeit der Auffassung, die in gemeinsamen Besprechungen herauszuarbeiten ist, muss vielmehr so aussehen, dass Einigkeit darüber besteht, welche Seite des bestimmten Problems von der deutschen Geschichtsschreibung, welche Seite von der polnischen betont werden wird. “ ${ }^{\star 45}$

Vorderhand konnte man sich also lediglich darauf einigen, dass man sich uneins war; die nationalen Narrative standen sich bis auf Weiteres unversöhnlich gegenüber.

Zwischen zwei ungelenkten Historiographien könnten solche Differenzen angesichts einer äußerst belasteten Beziehungsgeschichte kaum erstaunen. Wie aber lässt sich der zutage tretende Gegensatz unter den Prämissen einer vorgeblich von beiden Seiten geteilten sozialistischen Geschichtsdeutung verstehen?

\footnotetext{
${ }^{44}$ Grundsätzlich positiv etwa Gerard Labuda, Próba nowego ukazania stosunków polsko-niemieckich w nauczaniu szkolnym [Versuch einer neuen Darstellung der deutsch-polnischen Beziehungen im Schulunterricht], in: Ders. (Hrsg.), Rozmowy polsko-niemieckie o przeszłości, Posen 1996, S. 403-415 [erstmals in: Przegląd Zachodni 12/11-12 (1956), S. 246-256]; vgl. auch Enno Meyer, Wie ich dazu gekommen bin: Die Vorgeschichte der deutsch-polnischen Schulbuchgespräche 1948-1971, Braunschweig 1988, S. 37.

${ }^{45}$ Ergänzungsbericht zum Schlussprotokoll der 1. Tagung der deutsch-polnischen Historikerkommission, 5. 11. 1956, in: ABBAW, ZIG 555.
} 
Hier wird ein Blick auf die Entwicklung der beiden Nachkriegshistoriographien nötig. Zunächst durchliefen die ostdeutsche und polnische Geschichtswissenschaft nach 1945 eine vergleichbare Entwicklung: Auf eine Phase der Duldung bürgerlicher Historiker ${ }^{46}$, bedingt durch das Werben der neuen Machthaber um gesellschaftliche Zustimmung und den Mangel an marxistischen Geschichtsinterpreten, folgte im Zeichen der Machtkonsolidierung vor Ort und stalinistischer Vorgaben aus Moskau ab 1948 eine Phase verschärfter Kontrolle und forcierter Umgestaltung $^{47}$. Zur Bewertungsrichtlinie der Nationalgeschichte wurde dabei ein historiosophisches Schema erhoben, das sämtliche historischen Erfolge den fortschrittlichen Volksmassen zuschrieb, alle Misserfolge hingegen der egoistischen Politik der besitzenden Klassen anlastete ${ }^{48}$. Die Nationalgeschichte zerfiel dadurch in zwei antagonistische Stränge, die mit den Prädikaten „progressiv“ und „reaktionär“ versehen wurden. Im Verhältnis zwischen den Staaten und Völkern sollten nationale Gegensätze der internationalen Klassensolidarität weichen, was der linientreue polnische Historiker Bogusław Leśnodorski ausdrücklich auch für das deutsch-polnische Verhältnis bekräftigte:

„Im hellen Licht der durch die Quellen bezeugten Wahrheit muss die Verbundenheit zwischen der polnischen und [...] der deutschen revolutionären Arbeiterbewegung dargelegt werden. Die diese Epoche behandelnden Forscher müssen [...] die gegen das Volk gerichtete, antinationale Haltung der Bourgeoisie, der Großgrundbesitzer und ihrer politischen Repräsentanten klar herausstellen." ${ }^{49}$

Nicht entlang nationaler, sondern entlang sozialer Scheidelinien galt es demnach zu differenzieren. Zum Zeitpunkt der Kommissionsgründung waren beide Partner dieser Sichtweise allerdings in ganz unterschiedlichem Maße verpflichtet, denn im Tauwetter des Jahres 1956 liefen die Entwicklungen in den zwei Ländern rasch wieder auseinander. In Polen wurde die neue Bewegungsfreiheit unverzüglich genutzt. In der Historikerschaft begann die Abrechnung mit der stalinistischen Orthodoxie bereits 1956 und erreichte ihren Höhepunkt zwei Jahre später auf dem VIII. polnischen Historikerkongress in Krakau, als insbesondere Tadeusz Manteuffel die Geschichtsklitterungen der Parteihistoriker um

\footnotetext{
${ }^{46}$ Für Polen siehe Andrzej Feliks Grabski, Zarys historii historiografii polskiej [Abriss zur Geschichte der polnischen Historiographie], Posen 2000, S. 199-204. Besonders augenfällig wird die Duldung der bürgerlichen Historiker in der Institution des Posener Westinstituts. Für die DDR siehe Sabrow, Diktat, S. $39 \mathrm{f}$.

${ }^{47}$ Allerdings betont Rautenberg die im Vergleich zur ostdeutschen Historikerzunft geringere Anfälligkeit der polnischen Historiographie für den stalinistischen Dogmatismus und begründet dies mit dem Umstand, dass sie „aus der Vorkriegszeit gerade auf dem Gebiet der Sozial-, Verfassungs- und Wirtschaftsgeschichte [...] über ein genügend feines Instrumentarium verfügte, um nicht der Gefahr allzu schematischer Betrachtungsweise zu erliegen“. Hans-Werner Rautenberg, Polen und das Baltikum in der Geschichtsschreibung der DDR, in: Hellmann (Hrsg.), Osteuropa, Bd. 1, S. 289-310, hier S. 290.

${ }^{48}$ Vgl. Grabski, Zarys, S. $211 \mathrm{f}$.

${ }^{49}$ Bogusław Leśnodorski, Die Geschichtswissenschaft im ersten Dezennium Volkspolens, in: Zeitschrift für Geschichtswissenschaft, Beiheft 3 (1956), S. 3-62, hier S. 47 f. Diese internationalistische Sichtweise hatte sich auf polnischer Seite 1956 schon weitgehend überlebt.
} 
Tadeusz Daniszewski ${ }^{50}$ schonungslos kritisierte $^{51}$. Ein dogmatischer Historischer Materialismus war damit diskreditiert; es erfolgte eine weitreichende Rückkehr zur traditionellen Nationalgeschichte ${ }^{52}$, der sich auch die Polnische Vereinigte Arbeiterpartei (PVAP) nicht gänzlich verschließen wollte. Die nationale Rückbesinnung des Regimes verkörperte Władysław Gomułka, der vor seiner zeitweiligen Entmachtung 1948 „Minister für die Wiedererlangten Gebiete“ gewesen war und der polnischen Westforschung als Erster Sekretär der PVAP nach 1956 zu neuer Blüte verhalf ${ }^{53}$. Nationaler Zusammenhalt, so die Botschaft, rangierte inskünftig wieder vor Völkerfreundschaft ${ }^{54}$. In diesem Kontext betrachteten es die Polen nicht länger als opportun, ,gleichsam eine Internationale marxistischer Historiker zu gründen “55.

Anders präsentierte sich die Lage in der DDR, wo parteikommunistische Historiker nach einer Phase der Verunsicherung ihre Positionen unbeschadet halten und in der Folge gar noch ausbauen konnten ${ }^{56}$. Im Ergebnis wurde hier weiterhin ein dialektisches Geschichtsbild gepflegt, das vom innernationalen Gegensatz progressiver und reaktionärer Kräfte ausging.

Die gegensätzlichen Geschichtsbilder von ostdeutschen und volkspolnischen Historikern reflektierten indes nicht nur den unterschiedlichen Grad der Destalinisierung, sondern bildeten auch die jüngsten historischen Erfahrungen beider Länder ab - zunächst die Zweistaatlichkeit Deutschlands gegenüber der staatlichen Einheit Polens, vor allem aber die unterschiedlichen Rollen beider Länder

\footnotetext{
${ }^{50}$ Ihm unterstand das Parteigeschichtliche Institut beim ZK der Polnischen Vereinigten Arbeiterpartei (Polska Zjednoczona Partija Robotnicza PZPR).

51 Vgl. Grabski, Zarys, S. 213. Text des Referats bei Stanisław Trawkowski (Hrsg.), Historyk wobec historii. Rozprawy nieznane, pisma drobne, wspomnienia [Historiker und Historie. Unbekannte Aufsätze, Briefe, Erinnerungen], Warschau 1976.

52 Besonders dezidiert vertritt Borejsza die These vom nicht-kommunistischen Charakter der polnischen Geschichtswissenschaft seit Ende der 1950er Jahre; vgl. Jerzy Borejsza, Einige Anmerkungen zur polnischen Zeitgeschichtshistoriographie nach 1989, in: Alojz Ivaniševic/ Andreas Kappeler/Walter Lukan u. a. (Hrsg.), Klio ohne Fesseln? Historiographie im östlichen Europa nach dem Zusammenbruch des Kommunismus, Frankfurt a. M. 2002, S. 247-258. Kritisch dazu die Erwiderung von Klaus Bachmann, Noch mehr Anmerkungen zur polnischen Historiographie, in: Ebenda, S. 259-266.

53 Vgl. Neumann, Polens Westarbeit, S. 168.

${ }_{54}$ Diese integrative Tendenz der polnischen Nationalhistoriographie fiel auch Enno Meyer auf, der sie wie folgt begründete: „Da für Polen Teilung, Fremdherrschaft sowie Auflehnung dagegen wesentlicher Inhalt der Geschichte seit dem 18. Jahrhundert sind, betonen die polnischen Lehrbücher alles, was Kontinuität, Selbständigkeit und Geschlossenheit Polens in ethnischer, kultureller und politischer Hinsicht bestätigt. Umstände, die diesem Bild der Kontinuität nicht entsprechen, werden vernachlässigt.“ Meyer, Schulbuchgespräche, S. 39.

55 Reaktion der polnischen Historiker auf der 1. Sitzung der DPHK, als sie von ihren ostdeutschen Kollegen auf Pläne des italienischen Gramsci-Instituts angesprochen wurden, eine „Konferenz der marxistischen Historiker aller Länder“ auszurichten. Ergänzungsbericht zum Schlussprotokoll der 1. Tagung der deutsch-polnischen Historikerkommission, 5. 11. 1956, in: ABBAW, ZIG 555.

56 Vgl. Sabrow, Diktat, S. 77-81, S. 87, S. 92 u. S. 94; Ilko-Sascha Kowalczuk, Legitimation eines neuen Staates. Parteiarbeiter an der historischen Front. Geschichtswissenschaft in der SBZ/ DDR 1945 bis 1961, Berlin 1997, S. 316.
} 
im Zweiten Weltkrieg als Täter- und Opfernation. Daraus erwuchsen gänzlich unterschiedliche Bewertungen der eigenen Nationalgeschichte: In Polen konnte diese überwiegend positiv konnotiert werden - von den Anfängen der polnischen Staatlichkeit bis zur Volksrepublik spannte sich der Bogen eines legitimen und letztlich erfolgreichen Kampfes um nationale Selbstbehauptung und Entfaltung. In Deutschland hingegen, wo man sich nach 1945 mit dem Erbe des Nationalsozialismus konfrontiert sah, verbot sich eine ungebrochene Identifizierung mit der eigenen Geschichte. Dennoch musste sich die DDR um positive Anknüpfungspunkte in der deutschen Vergangenheit bemühen, wollte sie im in- und ausländischen Bewusstsein mehr darstellen als eine willfährige sowjetische Besatzungszone. Es galt daher, die deutsche Geschichte auf positive und negative Traditionen zu überprüfen, wobei das marxistisch-leninistische Geschichtsmodell mit seiner antagonistischen Grundkonzeption überaus gelegen kam. Es wurde, wie Martin Sabrow darlegt, zur „narrative[n] Grundlage“ der sogenannten „Zwei-Linien-Theorie“, der zufolge sich die deutsche Geschichte in eine „reaktionäre“ und eine „fortschrittliche" Linie unterteilte. Demnach bildeten mittelalterliche Ostexpansion, fürstliche Territorialisierung der Neuzeit, Sieg der Konterrevolution 1948, Bismarcks Reichseinigung von oben, Krieg und NS-Herrschaft eine negative Linie, die in die BRD mündete, während die Revolutionen von 1525, 1848 und 1918 Etappen einer positiven Linie markierten, die auf die DDR hinführte ${ }^{57}$.

Eine solche Sichtweise hatte keineswegs nur innerdeutsche Implikationen. Vielmehr wurde sie, einmal zur offiziellen Geschichtssicht avanciert, auch nach außen vertreten, wie eine Konzeption zur internationalen Arbeit auf dem Gebiet der Geschichtswissenschaft aus dem Jahr 1966 belegt:

„Die gesamte internationale Arbeit der Historiker der DDR muss darauf gerichtet sein, unser marxistisch-leninistisches Geschichtsbild [...] im Ausland zu verbreiten. [...] Dabei ist von den beiden entgegengesetzten Grundlinien in der Geschichte des deutschen Volkes auszugehen:

- der Rolle der progressiven, humanistischen Kräfte, insbesondere der revolutionären deutschen Arbeiterbewegung und den Lehren aus ihrem 120jährigen Kampf [...];

- der Einschätzung der reaktionären, nach innen anti-nationalen und nach außen aggressiven Kräfte, die heute im westdeutschen Staat mit Hilfe der ,Ostforschung“ und der ,Sowjetologie“ ihre alten Pläne durchsetzen wollen. “58

\footnotetext{
${ }^{57}$ Besonders pointiert wurde diese Sichtweise in einer Programmschrift dargelegt, welche die Staatsführung der DDR am 17.6. 1962 von einem eigens einberufenen Nationalkongress sanktionieren ließ. Demnach habe in der DDR ,alles seine Heimstatt, was es in der deutschen Geschichte an Gutem, Schönem und Fortschrittlichen gibt", in der Bundesrepublik werde hingegen ,alles konserviert und belebt, was es in der deutschen Geschichte an Rückständigem, Barbarischem und Unmenschlichem, an Dummheit und Borniertheit" gebe. Die geschichtliche Aufgabe der Deutschen Demokratischen Republik und die Zukunft Deutschlands, in: Zeitschrift für Geschichtswissenschaft 10/1 (1962), S. 758-786, hier S. 760.

${ }_{58}$ Entwurf einer Konzeption über die internationale Arbeit auf dem Gebiet der Geschichtswissenschaft, 29. 8.1966, S. 10 f., in: ABBAW, Arbeitsgemeinschaft der gesellschaftswissenschaftlichen Institute und Einrichtungen 72/1.
} 
Mithin standen sich in der DPHK von Beginn an eine dualistisch konzipierte ostdeutsche und eine holistisch angelegte polnische Nationalgeschichte gegenüber. Wie sich dieser Gegensatz auswirkte, verdeutlicht ein Beispiel aus dem Jahr 1958, als Felix-Heinrich Gentzen als Vertreter der gemeinsamen Kommission dem VIII. polnischen Historikerkongress beiwohnte - also eben jenem Kongress, auf dem die Entstalinisierung in der polnischen Geschichtswissenschaft zum Durchbruch gelangte. Bestürzt musste Gentzen feststellen, wie die harmonischen Klänge deutsch-polnischer Klassensolidarität auf polnischer Seite nun wieder von nationalen Dissonanzen überstimmt wurden:

„Ein [...] Redner [...] traf die Feststellung, dass es [bei den oberschlesischen Aufständen] nicht um einen Kampf der polnischen Arbeiter gegen die deutsche oder polnische Bourgeoisie gegangen sei, sondern um dem Kampf der Polen gegen die Deutschen. Es sei an der Zeit, dass ,der echte Nationalheld Korfanty' (einer der extremsten Vertreter des polnischen Nationalismus und Agent der polnischen Großbourgeoisie[)] endlich auf den Platz gestellt würde, der ihm gebührt. Auch dieser Bemerkung wurde lauter Beifall gezollt. [...] Ich machte diesen Beitrag zum Gegenstand einer Bemerkung [...]. Ich wies dabei auf die Notwendigkeit hin, angesichts der Vorbereitung eines neuen Weltkrieges durch den westdeutschen Imperialismus, der Volkspolen und die DDR in gleicher Weise bedrohte, dieser Gefahr gemeinsam zu begegnen. Dies könne aber nicht durch eine nationalistische Konzeption der deutsch-polnischen Feindschaft erfolgen, wie sie von einem der Diskussionsredner unter Beifall des Publikums vertreten worden sei. Als Deutschen, der aus der Geschichte die richtigen Lehren gezogen hat und für das polnische Volk Gefühle aufrichtiger Freundschaft hege, habe mich diese Feststellung und die Reaktion des Publikums darauf besonders betrübt. Trotz der 6 Millionen durch den deutschen Faschismus ermordeten Polen dürfe man nicht die Tatsache des gemeinsamen Kampfes, Leidens und Sterbens Hunderttausender deutscher und polnischer Antifaschisten gegen den gemeinsamen Feind, den deutschen Faschismus, Imperialismus und Militarismus [vergessen $]^{59}$. Dieses seien Traditionen, auf denen man aufbauen müsse, wobei die deutschen und die polnischen Historiker im Augenblick die besonders wichtige Aufgabe des Kampfes gegen die westdeutsche Ostforschung und der Herausarbeitung der freundschaftlichen Traditionen in der Geschichte des deutschen und des polnischen Volkes hätten. “60

\footnotetext{
${ }^{59}$ Im Original: „verwechseln“ - wohl ein Flüchtigkeitsfehler.

${ }^{60}$ Felix-Heinrich Gentzen, Bericht über den VII. Kongress polnischer Historiker vom 12.-17. 9. 1958 in Kraków, in: ABBAW, ZIG 710/2 (Hervorhebungen des Autors). In auffälligem Kontrast zu den hier referierten Auffassungen steht ein 1956 publizierter, von Leśnodorski noch im stalinistischen Geist verfasster Forschungsbericht, der den von Gentzen propagierten Auffassungen sehr viel näher kommt. Darin wird eine Abhandlung von Kazimierz Popiołek zu den schlesischen Aufständen dafür kritisiert, dass sie „noch das Schema zweier einander feindlich gegenüberstehenden Nationalitäten auf[weist] - und was noch schlimmer ist, sie steht unter dem Einfluß der schädlichen Korfanty-Legende." Leśnodorski, Geschichtswissenschaft, S. 49 f.
} 
Mit seinem Versuch, die gemeinsamen Interessen des deutschen und des polnischen Proletariats zu beschwören, stieß Gentzen freilich auf taube Ohren. Eine solche Deutung der Geschichte hätte die Polarisierung in Täter und Opfer relativiert, die die Nationalitätenkämpfe des 19. Jahrhunderts und insbesondere der Zweite Weltkrieg zwischen beiden Völkern begründet hatten. Dieser Gegensatz galt vielen polnischen Historikern indes als Höhepunkt eines jahrhundertealten deutsch-polnischen Antagonismus und gleichzeitig als schlagendes Argument, um die deutschen Kollegen von der polnischen Lesart dieses Konfliktes zu überzeugen. Es ging also nicht nur darum, die offensichtliche Schuld Deutschlands am Zweiten Weltkrieg anzuerkennen, sondern in ihrem Licht darüber hinaus auch die polnische Meistererzählung der deutsch-polnischen Beziehungen seit dem Mittelalter als maßgebliche Interpretation der gemeinsamen Kommission zu etablieren.

\section{Themen und Muster der Auseinandersetzung}

Auf welche „Verhandlungsmasse“ bezog sich nun das deutsch-polnische Ringen um eine national nivellierende beziehungsweise national akzentuierte Beziehungsgeschichte? Einen Eindruck von den thematischen Horizonten der Kommission vermitteln ihre alljährlichen wissenschaftlichen Kolloquien. Dem Selbstverständnis der Kommission folgend können diese zunächst der reaktionären oder progressiven Traditionslinie zugeordnet werden ${ }^{61}$, um dann eine weitere Differenzierung zu erfahren. Daraus ergibt sich die folgende Einteilung ${ }^{62}$ :

1. Dem Kampf mit der reaktionären Tradition lassen sich folgende - hier in drei Kreisen gesammelte - Themen zuordnen:

a) Vergangenheitsbewältigung: Schulbuchvergleich (1956), Zweiter Weltkrieg (1960, 1967, 1989), Versailler Vertrag (1961), Vertrag von Locarno 1925 (1964), deutsche und polnische Minderheiten im Nachbarland 1918-1939 (1965), Brandenburg-Preußen (1986);

\footnotetext{
${ }^{61}$ W. Schmidt, Vorschlag zur gemeinsamen Auszeichnung der bilateralen Historikerkommission der DDR und der VR Polen durch die Akademie der Wissenschaften der DDR und die Polnische Akademie der Wissenschaften im Jahre 1988, Berlin, 16. 12. 1987, in: ABBAW, ZIG 710/2.

${ }^{62}$ Die Themenstellungen werden aus Platzgründen paraphrasiert - und nicht im Wortlaut - wiedergegeben. Sie wurden zusammengestellt nach: DDR-Sektion der Kommission der Historiker der DDR und der Volksrepublik Polen (Hrsg.), 30 Jahre; ergänzend ab 1984 nach: Bleiber an Tazbir, Berlin, 14.3. 1984, in: ABBAW, ZIG 171; Protokoll der XXXII. Tagung, Wrocław, 20.9. 1985, in: ABBAW, ZIG 710/1; Protokoll der XXXIII. Tagung, Potsdam, 23. 5. 1986, Protokoll der XXXIV. Tagung, Warschau, 16.10. 1987, und Protokoll der XXXV. Tagung, Leipzig, 3. 6. 1988, in: Ebenda; Bericht über die XXXVI. Tagung, Rostock, 10. Juni 1989, in: ABBAW, ZIG 710/2. Vgl. die teilweise ähnlichen Themen der (west-) deutsch-polnischen Schulbuchkommission: Widerstand im Zweiten Weltkrieg (1977), Vormärz (1979), Aufklärung (1980), Industrialisierung und Arbeiterbewegung (1983). Etwas abweichend systematisiert Stelzig, Geschichtsbild, S. 245-295, der folgende Themenkreise bildet: Das Problem der Oder-Neisse-Grenze, deutschpolnische revolutionäre Beziehungen bis 1945, polnisch-deutsche Beziehungen im 20. Jahrhundert, die Beziehungen DDR-Polen, Geschichte und Methodologie der Geschichtswissenschaft, Kulturgeschichte, Auseinandersetzung mit der westlichen Geschichtsschreibung.
} 
b) Auseinandersetzung mit dem reaktionären Gegner vor 1945: Ostmarkenverein (1963), deutsche Sozialdemokratie und polnische Frage $(1959)^{63}$, deutsche politische Parteien und Strömungen gegenüber Polen 1850-1900 (1968);

c) Auseinandersetzung mit dem reaktionären Gegner nach 1945: Westdeutsche Ostforschung (1958-60), Darstellung der deutsch-polnischen Beziehungen in den westdeutschen Geschichtswerken (1962, vgl. Bezugnahme auf Enno Meyers Thesen 1956).

2. Als Hervorhebung der progressiven Tradition sind folgende Themenkreise zu verstehen:

a) Behandlung der progressiven Tradition nach 1945: Oder-Neiße-Grenze (1956), Stand der beiden sozialistischen Geschichtswissenschaften (1957 und $\left.1975^{64}\right)$, Entwicklung der zwei volksdemokratischen Staaten (1961), Nationalisierung der Industrie (1966), Beziehungen DDR-VRP (1970), sozialistische Umgestaltung und wissenschaftlich-technische Revolution (1971), 25 Jahre DDR/30 Jahre VRP (1975), 30 Jahre DDR/35 Jahre VRP (1979), 35 Jahre DDR/40 Jahre VRP (1984), Umwälzungen in der SBZ und VRP 1944/45-1949 (1985);

b) Aufspüren der progressiven Tradition vor 1945: Novemberrevolution 1918 (1969), Gründung von KPD und KPP (1978), revolutionäre deutsch-polnische Völkerfreundschaft in den 1830er Jahren (1980), fortschrittliche Freiheitsbewegungen in Deutschland und Polen vor 1848 (1981), Rosa Luxemburg und Julian Marchlewski (1987), revolutionäre Demokraten im Vormärz und 1848 (1988);

c) Kulturbeziehungen: Deutsch-polnische Kulturbeziehungen, insbesondere zwischen DDR und VRP (1972), Urbanisierung im 19. und 20. Jh. (1974), Kulturgeschichte 1800-1850 (1976), Aufklärung in Deutschland und Polen (1977), Reformation in Deutschland und Polen (1982), deutsch-polnische Kulturbeziehungen seit 1850 (1983), soziale, politische und kulturelle Wandlungen in Mitteleuropa im 17. Jh. (1984).

Bilanzierend fällt auf, dass die Beschäftigung mit der reaktionären Traditionslinie (und damit auch die Vergangenheitsbewältigung) sich im Wesentlichen auf die ersten zehn und die letzten fünf Jahre (1985-1990) der Kommissionsarbeit beschränkte und vorwiegend - aber nicht ausschließlich, wie wir noch sehen werden - auf die deutsche Seite gerichtet war. Demgegenüber wurden die progressiven Traditionen der gemeinsamen Beziehungsgeschichte über den gesamten Zeitraum thematisiert, blieben zunächst aber auf die Selbstbespiegelung der neuen sozialistischen Staaten beschränkt. Erst seit den siebziger Jahren wurden gedeihliche deutsch-polnische Beziehungen - zunächst politisch-sozialer, dann

\footnotetext{
${ }^{63}$ Hier erfolgte eine Verurteilung der „rechten Sozialdemokratie“v. a. durch die DDR-Seite, die polnische Seite zeigte sich wohlwollender; vgl. Stelzig, Geschichtsbild, S. 252.

${ }_{64}$ Die 22. Sitzung der DPHK beschäftigte sich mit den Errungenschaften der polnischen Historiker zum 30. Jahrestag der Volksrepublik Polen und jenen der ostdeutschen Historiker zum 25. Jubiläum der DDR. Czesław Madajczyk an Stanisław Krzykała, Warschau, 15. 11. 1974, in: Instytut Historii PAN w Warszawie (künftig: IHPAN), 5/107, Bl. 181.
} 
zunehmend kultureller Art - vor der Epochenwende von 1945 aufgespürt. Dabei akzentuierte sich allmählich eine gewisse Asymmetrie zugunsten der deutschen kulturellen Ausstrahlung auf den Nachbarn - fassbar in der Behandlung von Themen wie der Novemberrevolution oder der Reformation. Gehen wir davon aus, dass Vergangenheitsbewältigung vorwiegend im Interesse der Polen lag (und von den Deutschen nur soweit gewünscht wurde, wie sie zur Exkulpierung der DDR nötig war), während die Behandlung des progressiven Beziehungserbes mit unterschwelliger Betonung deutscher Einflüsse auf den polnischen Nachbarn eher deutschen Wünschen entsprach, so scheint hier ein sich wandelndes Kräfteverhältnis zwischen Polen und Deutschen hervorzutreten.

\section{Selbstbewusste Polen, bescheidene Ostdeutsche}

In den ersten Jahren der Kommission nutzten die Polen die Gunst der Stunde, um den Deutschen im Ringen um konkurrierende Nationalmythen und umstrittene Erinnerungsorte symbolträchtige Konzessionen abzutrotzen ${ }^{65}$. Meist erfolgten diese Initiativen zwar im Zusammenhang mit der Historikerkommission, aber außerhalb ihres institutionellen Rahmens in Kontexten, in denen eine polnische Majorisierung der deutschen Partner möglich war - beispielsweise auf polnischen oder internationalen, jedoch in Polen ausgerichteten Kongressen mit deutschen Gästen. Im Rahmen von Jahresfeierlichkeiten, Publikationen und Konferenzen zum 1000-jährigen Bestehen Polens, zur Polonität Pommerns ${ }^{66}$, Schlesiens, Danzigs $^{67}$ oder Copernicus ${ }^{68}$, ja gar zum slawischen Charakter der Lausitzer Kultur ${ }^{69}$ wurden die DDR-Historiker von ihren polnischen Kollegen involviert und unter sanftem Druck dazu gebracht, ihr Einverständnis mit der jeweiligen polnischen Sichtweise zu erklären. Mit einem Anflug von Erschöpfung notierte Heinrich Scheel 1958 die für das nächste Jahrfünft anstehenden polnischen Jubiläen, die nach ostdeutscher Beteiligung verlangten:

\footnotetext{
${ }^{65}$ Zum Begriff historischer Mythen vgl. Yves Bizeul, Politische Mythen und Rituale in Deutschland, Frankreich und Polen, Berlin 2000. Der Begriff des Erinnerungsortes stammt von Pierre Nora.

${ }^{66}$ Einbezug ostdeutscher Historiker in die Internationale Pommernkunde-Konferenz 1960 in Stettin; ostdeutsche Unterstützung bei der Publikation einer polnischen Rezension westdeutscher Pommern-Literatur 1964.

${ }^{67}$ Vgl. Stelzig, Geschichtsbild, S. 239.

${ }^{68}$ Polen ehrte den Astronomen 1953 mit großem Aufwand. Bereits die wenig zwingende Wahl des Jubiläumsjahres - 480 Jahre nach der Geburt und 410 Jahre nach dem Tod - macht deutlich, dass hier die erstbeste Gelegenheit ergriffen wurde, Copernicus für die eigene Nation zu beanspruchen. Im Vorfeld der ostdeutschen Beteiligung an den Feierlichkeiten wurde Copernicus von polnischer Seite konsequent als „berühmter polnischer Gelehrter“ bezeichnet, während die ostdeutschen Historiker anfangs jede nationale Zuordnung vermieden und erst nach beharrlichem Insistieren der Polen schließlich die Sprachregelung vom „polnischen Gelehrten“ übernahmen. Akademieleitung an Instytut Historii PAN, 17.6., 5.8. und 24.10. 1953, in: ABBAW, Akademieleitung 488.

${ }^{69}$ So wurden die ostdeutschen Historiker um Begutachtung einer polnischen Geschichte Pommerns gebeten, die im ersten Band auch auf den polnischen Charakter der Lausitzer Kultur eingehen sollte. Gerard Labuda an Johannes Schildhauer, Posen, 17. 9. 1968, in: ABBAW, ZIG 710/4.
} 
„1960: Chopins 150. Todestag.

1960: 550. Jahrestag der Schlacht bei Grunwald.

1963: Die erste schriftliche Erwähnung des polnischen Staates vor 1000 Jahren.

1963: 100. Jahrestag des Januaraufstandes 1863.

1964: 20. Jahrestag des Bestehens Volkspolens.

1964: 600. Jahrestag der Entstehung der Jagiellonen-Universität in Krakau“"70.

Zweifellos sollte diese Parade nationaler Errungenschaften Polens historischen Leistungsausweis als Kulturnation und Großmacht vergegenwärtigen und damit nicht zuletzt auch seinen Bestand in den Grenzen von 1945 legitimieren. Denn der Fluchtpunkt dieser Bemühungen blieb stets die Grenze an Oder und Neiße. Bereits auf ihrer zweiten Tagung gelobte die Kommission, diese „Friedensgrenze zwischen Deutschland und Polen [...] mit allen Kräften sichern" zu wollen und bezeichnete es als „die besondere Aufgabe der Historiker beider Länder, die wissenschaftliche Forschung zur Oder-Neiße-Grenze [...] zu vertiefen “71. Gleichzeitig zeigten sich die Polen jedoch unzufrieden mit ostdeutschen Stellungnahmen in dieser Kardinalfrage der nachbarschaftlichen Beziehungen. Henryk Zieliński kritisierte in diesem Zusammenhang gleich drei ostdeutsche Titel, denen er vorwarf, die angeblich periphere Rolle der ehemaligen Ostgebiete in der deutschen Wirtschaft nicht klar genug betont zu haben und ihre enge historische Verbindung mit Zentralpolen zu verschleiern ${ }^{72}$. Damit wurden die DDR-Historiker in die Nähe der westdeutschen Ostforschung gerückt, die durch die neue Grenze vitale Wirtschaftszusammenhänge durchtrennt sah und Polen vorwarf, seinerseits an der Integration der fraglichen Gebiete zu scheitern. Die Ostdeutschen gaben schuldbewusst zu, das Thema seit 1950 vernachlässigt zu haben, und bestätigten 1957 in der Subkommission Schlesien, dass die „Vernachlässigung der Ostprovinzen (besonders Schlesiens) im Rahmen der deutschen Wirtschaft“ zu den Themen gehöre, „deren Bearbeitung durch deutsche und polnische Historiker notwendig, bzw. wünschenswert wäre “73.

Doch nicht nur unterschiedliche Bewertungen brachte das heikle Thema an den Tag - es offenbarte darüber hinaus auch die grundlegend verschiedenen Argumentationsweisen beider Seiten, wie Gentzen rückblickend in einem Bericht an die Abteilung Wissenschaften des ZK der SED freimütig zugab:

„[Es] wurde [in der 2. Kommissionstagung von 1956] festgestellt, dass die Argumentation zur Begründung der Oder-Neiße-Grenze auf Grund der in beiden Ländern vorhandenen unterschiedlichen historischen, politischen und psychologischen Voraussetzungen nicht die gleiche sein könne. So könne z. B. eine histo-

\footnotetext{
${ }^{70}$ Heinrich Scheel, Beschlußprotokoll der deutschen Sektion der deutsch-polnischen Historikerkommission, 10. 10. 1958, in: ABBAW, ZIG 710/1.

${ }^{71}$ Kuczynski/Leśnodorski, Schlussprotokoll der 2. Tagung der deutsch-polnischen Historikerkommission, Berlin, 17. 11. 1956, in: ABBAW, ZIG 555.

${ }^{72}$ Vgl. Kwartalnik Historyczny 64 (1957), S. 237; Stelzig, Geschichtsbild, S. 245 f. Die kritisierten Darstellungen stammten von Paul Wandel, Rudi Goguel/Heinz Pohl und Felix-Heinrich Gentzen.

${ }^{73}$ Zusatzprotokoll der Subkommission „Schlesien“, Leipzig, 4. 12. 1957, in: ABBAW, ZIG 555.
} 
rische oder ethnographische Begründung der Oder-Neiße-Grenze, wie sie in der poln. Propaganda üblich ist, dem dt. Leser gegenüber nicht dargeboten werden, zumal diese Begründung zu einem Bumerang für revisionistische Forderungen werden könne. Auf der anderen Seite sei das Argument der Wiedergutmachung des am poln. Volke begangenen Unrechtes und der Garantie der staatlichen Sicherheit Polens für die poln. Propaganda kein überzeugendes Argument. “74

Eine gemeinsame Argumentationsweise ließ sich somit kaum herbeiführen. Immerhin leisteten die Ostdeutschen 1959 mit einer umfangreichen Dokumentensammlung zur Oder-Neiße-Linie propagandistische Nacharbeit - freilich erst, nachdem eine revisionistische westdeutsche Darstellung eine Entgegnung erfordert hatte ${ }^{75}$.

Mochte man sich ostdeutscherseits auch nicht immer leichten Herzens von historischen Besitzständen trennen, so ging man doch rasch dazu über, unhaltbar gewordene Ansprüche mit großer Geste als chauvinistische Altlasten zu verabschieden. Dem zollten selbst skeptische polnische Historiker der alten Schule zunächst Anerkennung. So fand Kazimierz Tymieniecki 1954 auf einer eigens einberufenen Diskussion des von Leo Stern vorgelegten Arbeitsplans für den ersten Band der Geschichte Deutschlands (bis 1400) lobende Worte:

„In der Darstellung der Geschichte Deutschlands im Osten Europas gelingt [dem Konzept] der Verzicht auf aggressive Tendenzen und ein sehr gerechtes Urteil in Bezug auf die dort ansässigen Völker, insbesondere die Slawen, worin es eher an die deutsche Wissenschaft von vor hundert Jahren erinnert." ${ }^{\text {“76 }}$

Der konsequente Verzicht auf revisionistische Positionen verlieh dem antifaschistischen Gründungsmythos der $\mathrm{DDR}^{77}$ anfänglich eine gewisse Glaubwürdigkeit. Damit ließen sich auch nationalsozialistische Altlasten zunächst erstaunlich reibungslos aus der Vorgeschichte des sozialistischen Deutschland entsorgen. Geradezu exemplarisch tritt dies im Umgang der ostdeutschen Historikerschaft mit der Vergangenheit der eigenen Zunft zutage: Nachdem die bilaterale Kommission

\footnotetext{
${ }^{74}$ Felix-Heinrich Gentzen, Einschätzung der Forschungsarbeiten auf dem Gebiet der Geschichte Polens seit 1955, 27. 8. 1962, in: BA Berlin, Stiftung Archiv der Parteien und Massenorganisationen der DDR (SAPMO), DY 30/IV 2/9.04/98.

${ }^{75}$ Vgl. Rudi Goguel (Hrsg.), Polen, Deutschland und die Oder-Neiße-Grenze, Berlin 1959, offenbar als Reaktion auf Gotthold Rhode/Wolfgang Wagner, Quellen zur Entstehung der Oder-Neiße-Linie in den diplomatischen Verhandlungen während des Zweiten Weltkrieges, Stuttgart $1956\left({ }^{2} 1959\right)$, sowie Wolfgang Wagner, Die Entstehung der Oder-Neiße-Linie in den diplomatischen Verhandlungen während des Zweiten Weltkrieges, Stuttgart 1953. Siehe auch Eduard Mühle, Für Volk und deutschen Osten. Der Historiker Hermann Aubin und die deutsche Ostforschung, Düsseldorf 2005, S. 427.

${ }^{76}$ Protokół z zebrania Katedry Historii Powszechnej w dniu 1 kwietnia 1954 [Protokoll der Zusammenkunft am Lehrstuhl für allgemeine Geschichte am 1. April 1954], Thorn, 1. 4. 1954, in: Archiwum PAN w Warszawie (künftig: APAN-W), III-192/45, Bl. $63 \mathrm{f}$. Ihre Gleichsetzung mit der liberalen deutschen Wissenschaft des 19. Jahrhunderts dürfte den DDR-Historikern freilich kaum gefallen haben.

77 Vgl. Herfried Münkler, Antifaschismus und antifaschistischer Widerstand als politischer Gründungsmythos der DDR, in: Aus Politik und Zeitgeschichte B 45 (1998), S. 16-29.
} 
bereits 1958 zur westdeutschen Ostforschung getagt hatte, machten die ostdeutschen Historiker das Thema zum Gegenstand einer umfangreichen Wanderausstellung unter dem Titel „Wissenschaft im Dienste des ,Dranges nach Osten““, die 1960 mit Unterstützung der polnischen Partner auf Tournee in fünf polnische Universitätsstädte (Breslau, Krakau, Lublin, Warschau und Stettin) geschickt wurde, wo sie insgesamt fast 50000 Besucher anzog ${ }^{78}$. In der Ausstellung wurde die deutsche Ostforschung vor, während und nach dem Zweiten Weltkrieg anhand von Quellenauszügen und erläuternden Texten dokumentiert und scharf verurteilt ${ }^{79}$. Aufs Korn genommen wurden insbesondere Theodor Oberländer, Hermann Aubin, Hans Koch, Peter-Heinz Seraphim und Eugen Lemberg, die im wissenschaftlichen und politischen Leben der Bundesrepublik exponierte Positionen einnahmen ${ }^{80}$.

Das polnische Publikum verstand die Ausstellung mehrheitlich als ehrliche Aufarbeitung der jüngeren deutschen Historiographiegeschichte ${ }^{81}$. Weitgehend

${ }^{78}$ Dieses Interesse war sicherlich auch der maßlosen Überschätzung der bundesrepublikanischen „Ostforschung“ durch die Feindbild-Propaganda der volksdemokratischen Staaten geschuldet. Als Beispiel vgl. Jozef Szlapczynski/Tadeusz Walichnowski, Nauka w ślubie ekspansji i rewizjonizmu [Wissenschaft im Dienste von Expansion und Revisionismus], Warschau 1969. Der Titel wurde durch eine wohlwollende Rezension im Parteiorgan der PVAP sanktioniert, wobei folgende Angaben referiert wurden: „[...]in Westdeutschland gibt es etwa 200 Ostforschungszentren mit insgesamt 2000 Wissenschaftlern und wissenschaftlich-technischen Mitarbeitern [...]. Die Kosten der Ostforschung belaufen sich auf mindestens 100 Mill. DM jährlich. In allen westdeutschen Schulen wird ,Ostkunde“ gelehrt, [...] Professoren der Ostforschung sind in allen Ministerien, in Presse, Rundfunk und Fernsehen anzutreffen. Westdeutsche Ostforscher haben konkrete ,Vorschläge' für Polen ausgearbeitet, wobei der deutsche Nationalismus in solchen Fragen wie Oder-Neiße-Grenze oder das Problem der Vertriebenen ausgenutzt werden sollen." Zycie Partii 9/1969, S. 40 f., hier zit. nach der Arbeitsübersetzung von Renate Schilling für das IML beim ZK der SED vom 24. 10. 1969, in: ABBAW, ZIG 555.

${ }^{79}$ Den Ausstellungskatalog gab Goguel heraus. Rudi Goguel (Hrsg.), Wystawa: Nauka w służbie „Drang nach Osten“, zorganizowana przez Sekretariat Stanu do Spraw Szkolnictwa Wyższego i Zawodowego Niemieckiej Republiki Demokratycznej przy współpracy Ministerstwa Szkolnictwa Wyższego Polskiej Rzeczypospolitej Ludowej i eksponowana w polskich orodkach uniwersytekkich [Eine Ausstellung: Wissenschaft im Dienst des „Drangs nach Osten“, veranstaltet vom Staatssekretariat für Hochschul- und Berufsschulangelegenheiten der Deutschen Demokratischen Republik unter Mitarbeit des Ministeriums für Hochschulwesen der Volksrepublik Polen und gezeigt in polnischen Universitätszentren], Berlin 1960.

${ }^{80}$ Vgl. Edward Mẹclewski, „Ostforschung“ im Dienste des Drangs nach Osten, in: Zeitschrift für Geschichtswissenschaft 9/2 (1961), S. 1112-1115, hier S. 1114. Der Propagandafeldzug gegen die westdeutsche „Ostforschung“ war von Moskau in den späten 1950er Jahren initiiert worden; vgl. z. B. V.T. Pašuto, Tak nazyvaemoe „Izučenie vostoka“ - Ideologija zapadnogermanskogo revanšizma [Die sogenannte „Ostforschung“ - Ideologie des westdeutschen Revanchismus], in: Voprosy Istorii 3 (1959), S. 60-76. Pašuto geht ausführlich auf die Oder-Neiße-Linie und ihre Infragestellung durch westdeutsche Historiker - u. a. Walter Schlesinger und Herbert Ludat ein. An der Humboldt-Universität zu Berlin bildete Rudi Goguel 1960 auf Geheiß des Staatssekretärs für das Hoch- und Fachschulwesen eine Abteilung für Geschichte der imperialistischen Ostforschung. Herder, Stellvertreter des Staatssekretärs für das Hoch- und Fachschulwesen an Prof. Schröder, Rektor der Humboldt-Universität zu Berlin, Berlin, 4. 4. 1960, in: AHUB, Rektorat nach 1945, 292, Bl. 15.

${ }^{81}$ Darauf lassen jedenfalls die Einträge in den Gästebüchern schließen. Anlage 5 zu Scheel, Die Wanderausstellung „Nauka w słubie Drang nach Osten“ (Wissenschaft im Dienste des Dranges 
unbemerkt blieb indes, wie die ostdeutschen Historiker sich selbst und ihren Staat jeder Verantwortung entzogen, indem sie das problematische Erbe in den Bahnen der Zwei-Linien-Konzeption ganz der Bundesrepublik anlasteten. Keine Zweifel an dieser Absicht ließ Heinrich Scheels Schlussbericht:

„Die politische Zielsetzung und Bedeutung der Ausstellung bestand vor allem darin, durch fundierte wissenschaftliche Dokumentation [...] die Gefahr des westdeutschen Revanchismus - vor allem seiner, wissenschaftlichen Wegbereiter" - in seiner ganzen Größe zu zeigen [...] Durch die Bekanntgabe zahlreicher bisher unveröffentlichter Dokumente über die Tätigkeit westdeutscher Ostforscher während der Weimarer Republik wie auch in der Nazizeit und im zweiten Weltkrieg trug die Ausstellung wesentlich zur Entlarvung der [...] historischen Wurzeln der psychologischen Kriegsführung Westdeutschlands bei. ${ }^{* 82}$

Dass man im Zuge der Recherchen zur Ostforschung auch auf Spuren späterer DDR-Historiker gestoßen war, allen voran Eduard Winter, wurde wohlweislich verschwiegen $^{83}$. Ebenso bezeichnend scheint, dass man von einer Präsentation der Ausstellung in der DDR selbst absah.

\section{Neues deutsches Selbstbewusstsein}

Die Attraktivität der dualistischen Konzeption bestand nicht nur darin, sich auf schmerzlose Weise vom negativen Erbe der deutschen Geschichte distanzieren zu können. Sie bot auch die Möglichkeit, ein positives Erbe zu beanspruchen und sich damit zu identifizieren. Diese Option begannen die ostdeutschen Historiker in der gemeinsamen deutsch-polnischen Kommission im Verlauf der sechziger Jahre einzufordern ${ }^{84}$. So erklärte Reinhold Jeske 1966 mit neuem Selbstbewusstsein:

nach Osten) in der Volksrepublik Polen (3. 10. 1960-23. 1. 1961). Abschlußbericht der Ausstellungsleitung, 1.3. 1961, in: ABBAW, ZIG 710/4.

82 Ebenda (Hervorhebungen des Autors).

${ }^{83}$ Allerdings zeigte man sich besorgt, Winter könnte sich in der Ostforschungs-Kampagne gegen die westdeutsche Historiographie befangen zeigen: „Offenbar ist Prof. Winter in seinem Auftreten gegen die westdeutschen Ostforscher (die er teilweise als Mitarbeiter von früher kennt) gehemmt." Zitat bei Sabrow, Diktat, S. 81; vgl. Christoph Kleßmann, DDR-Historiker und „imperialistische Ostforschung“. Ein Kapitel deutsch-deutscher Wissenschaftsgeschichte im Kalten Krieg, in: Deutschland Archiv 35 (2002), S. 13-31, hier S. 22. An einer Biographie Winters arbeitet Ines Kowalski (Bamberg). Auch Fritz Hartung und Wilhelm Unverzagt hatten Kontakte zur Ostforschung unterhalten, wie ihre Mitarbeit am Sammelband Albert Brackmann (Hrsg.), Deutschland und Polen. Beiträge zu ihren geschichtlichen Beziehungen, München 1933, zeigt. Aufsehenerregend dagegen die Übersiedlung des „konvertierten“ Ostforschers Eberhard Wolfgramm „aus Gewissensgründen“ in die DDR 1956 und seine anschließende Kritik an den ehemaligen Kollegen. Vgl. Kai Arne Linnemann, Das Erbe der Ostforschung. Zur Rolle Göttingens in der Geschichtswissenschaft der Nachkriegszeit, Marburg 2002, S 151.

${ }^{84}$ Auf nationaler Ebene hatte sich diese Hinwendung zum „positiven Erbe“ bereits seit 1952 abgezeichnet - bekräftigt 1955 mit dem Beschluss „Zur Verbesserung der Forschung und Lehre in der Geschichtswissenschaft der DDR“, der die Abkehr von der Misere-Theorie markiert und eine Rückbesinnung auf „grosse nationale Traditionen“ (Reformation, Bauernkriege, Befreiungskriege, 1848/49) angemahnt hatte. Stelzig, Geschichtsbild, S. 77. Die demgegenüber verzö- 
„Die deutsche Frage sollte in der Zukunft mehr denn je die konzeptionelle Orientierung unserer Arbeit in der Kommission bilden. [...] Es gilt dahingehend zu wirken, dass die DDR in der Historiographie und in der politischen Publizistik der benachbarten sozialistischen Länder stärker als bisher in ihrer grundsätzlichen Bedeutung für die weitere Entwicklung in Europa in Erscheinung tritt. (Und nicht in erster Linie nur als guter Verbündeter im Kampf gegen die revanchistische Politik des westdeutschen Imperialismus). [...] Themen, die sich auf die progressiven Richtungen in der deutschen Geschichte und ihren Beziehungen zu anderen Völkern beziehen, insbesondere aber die Themen zur Geschichte der deutschen Arbeiterbewegung können im Sinne der oben genannten Konzeption behandelt werden. ${ }^{65}$

Der Kommission stand damit eine heikle Neujustierung ihrer Sicht auf die gemeinsame Beziehungsgeschichte bevor. War die bisher vorherrschende Behandlung negativer deutscher Traditionen (Ostmarkenverein, Schlesische Aufstände, Zweiter Weltkrieg, Ostforschung) den patriotischen Bedürfnissen der polnischen Historiographie bisher gerade dort entgegengekommen, wo die Beziehungsgeschichte von nationalen Interessengegensätzen gezeichnet war, so drohte nun ein Konkurrenzverhältnis beiderseitiger Ansprüche auf positive Selbstdarstellung. Einmal mehr bestätigte sich der Eindruck aus den Anfangsjahren der Kommission, wonach „das, was für das deutsche Volk fortschrittlich war“, nicht immer „ebenso fortschrittlich für das polnische Volk“ gewesen sei ${ }^{86}$.

Widerspruchsfrei vereinen ließen sich positive Geschichtsbilder noch am ehesten in der Behandlung der jüngsten Geschichte ab 1949. So favorisierte die ostdeutsche Seite im Rahmen der gemeinsamen Konferenzen zunächst Aspekte der volksdemokratischen Entwicklung beider Staaten nach $1945^{87}$. Von hier aus arbeitete man sich seit den späten sechziger Jahren zurück über den Widerstandskampf deutscher und polnischer Antifaschisten im Zweiten Weltkrieg bis zum gemeinsamen Arbeiterkampf (Rosa Luxemburg, Julian Marchlewski), um schließlich bei der deutschen Polenfreundschaft der 1830er Jahre anzugelangen. Bald zeigten die DDR-Historiker allerdings eine für die polnische Seite irritierende Tendenz, immer weitere Bereiche ihrer Geschichte in den positiven Traditionsstrang einzuweben und ihre angeblich günstige Wirkung auf Polen herauszustreichen: So machten sie etwa den Einfluss der Reformation auf Polen ebenso zum

gerte Präsentation des „positiven deutschen Erbes“ auf internationaler Ebene war offenbar außenpolitischen Rücksichten geschuldet. Ihren Höhepunkt erreichte sie erst Mitte der siebziger Jahre.

${ }^{85}$ Reinhold Jeske, Stellungnahme zur Arbeit der Deutsch-Polnischen Historikerkommission (Abschrift), 22. 6. 1966, in: ABBAW, Nationalkomitee der Historiker 4. Hervorhebung im Original.

${ }^{86}$ Ergänzungsbericht zum Schlussprotokoll der 1. Tagung der deutsch-polnischen Historikerkommission, 5. 11. 1956, in: ABBAW, ZIG 555.

87 Es wurde eine Reihe entsprechender Gemeinschaftsprojekte initiiert, $u$. a. ein Dokumentenband zu den Beziehungen zwischen der VRP und der DDR, der in den 1970er Jahren begonnen, aber bis 1989 nur teilweise abgeschlossen wurde. Die entsprechenden Materialien in: ABBAW, ZIG 710/8. 
Thema gemeinsamer Konferenzen ${ }^{88}$ wie die Hanse $^{89}$ oder die Rolle der deutschen Kultur in Schlesien ${ }^{90}$. Das Thema Schlesien machte allerdings auch die Schranken sichtbar, die revisionismusverdächtigen ostdeutschen Interpretationen von der Pax Sovietica vorgegeben wurden: Die DDR-Seite konnte hier nur vereinzelt an deutsches Erbe erinnern, musste aber auch immer wieder Beiträge beisteuern, die deutsche Ansprüche auf Schlesien entkräfteten ${ }^{91}$. Ungeachtet solcher politisch auferlegter Beschränkungen mussten die deutscherseits gesetzten Akzente manchem Polen als Vexierbild alter Kulturgefälle-Paradigmen erscheinen.

\section{Preußen}

In den siebziger Jahren setzte zum größten Missfallen der Polen gar ein vorsichtiges Werben um eine partielle Rehabilitierung Preußens ein ${ }^{92}$. Bereits 1969 konstatierte Antoni Czubiński als Gast der Deutschen Historikergesellschaft an der

88 Die ostdeutsch-polnischen Interpretationsunterschiede hinsichtlich der Reformation Luthers hätten jahrhundertealte „nationale Voreingenommenheiten“ offenbart und sich keineswegs auf „Kleinigkeiten“ beschränkt, nach Franciszek Ryszka, Die Freiheit der Rede und die Unterstellung, eine schwierige und heikle Angelegenheit, in: Polityka vom 8. 1. 1983 (Deutsche Arbeitsübersetzung aus dem Nachlass Gotthold Rhodes, in: BA Koblenz, N 1445/152). Die Beschäftigung mit der Reformation wurde von polnischen Historikern damals nicht grundsätzlich abgelehnt, sondern sogar forciert betrieben, u. a. im Rahmen der Zeitschrift Odrodzenie i Reformacja w Polsce [Renaissance und Reformation in Polen] unter der redaktionellen Leitung von Janusz Tazbir. Dabei ging es den Polen allerdings um den Nachweis eigenständiger polnischer Entwicklungen, während ihre deutschen Kollegen die Strahlkraft des deutschen Vorbilds betonten.

${ }^{89}$ Dies im Rahmen der Hansischen Arbeitsgemeinschaft, die 1955 in Leipzig von Heinrich Sproemberg als ostdeutsche Fortführung des 1870 gegründeten und in Westdeutschland wiederbelebten Hansischen Geschichtsvereins ihre Arbeit aufgenommen hatte. Nach einigen Jahren der Zusammenarbeit mit dem westdeutschen Schwesterverband sonderte sich die Arbeitsgemeinschaft in den frühen sechziger Jahren ab. Polnische Historiker pflegten Kontakte zu beiden Vereinen.

${ }^{90}$ Dies vor allem in der Subkommission Schlesien. Zusatzprotokoll betr. Geschichte Schlesiens, 15. 11. 1956, in: ABBAW, ZIG 555.

${ }^{91}$ Eine Betonung des deutschen Erbes in Schlesien scheint etwa in folgenden Themenstellungen auf: „Die Entwicklung der deutschen Wissenschaft und Kultur in Schlesien und die Rolle Breslaus 1914-1945“; „Das deutsche Schrifttum, Kunst und Wissenschaft in Schlesien“; „Breslau als Zentrum des wissenschaftlichen Lebens 1850-1914“. Der Verneinung deutscher Ansprüche auf Schlesien dienten dagegen Themen wie: „Die Vernachlässigung der Ostprovinzen (besonders Schlesiens) im Rahmen der deutschen Wirtschaft“ oder „Das Scheitern der faschistischen Germanisierung in Oberschlesien im Ergebnis des nationalen Befreiungskampfes des polnischen Volkes“. Die ersten drei Zitate in: Zusatzprotokoll der Subkommission Schlesien zum Schlußprotokoll der 3. Tagung der deutsch-polnischen Historikerkommission, 4. 12. 1957, in: ABBAW, ZIG 555; das vierte in: Popiołek/Gentzen, Protokoll der Subkommission Schlesien, 27. 9. 1961, in: ABBAW, ZIG 710/1.

${ }^{92}$ Eine Übersicht über die Tendenzen und Fragestellungen der ostdeutschen Preußen-Historiographie bietet Hans Alexander Krauß, Die Rolle Preußens in der DDR-Historiographie. Zur Thematisierung der preußischen Geschichte durch die ostdeutsche Geschichtswissenschaft, Frankfurt a. M./Bern 1993. Zur Neubewertung Preußens in den siebziger Jahren insbesondere S. 85-124. 
Preußen-Konferenz in Halle eine neue „Tendenz, [...] die fortschrittlichen und demokratischen Traditionen Preußens stärker als bisher herauszuarbeiten“93. Daraufhin kam es 1970 in Posen zu einer ersten ostdeutsch-polnischen Konferenz zur Geschichte Preußens ${ }^{94}$. Eine Dekade später war die beobachtende Haltung der polnischen Seite offenem Unmut gewichen. „Inzwischen“, so ein nicht namentlich gekennzeichneter Bericht der DDR-Seite von 1980, ,ist uns von polnischer Seite [...] sehr nachdrücklich angedeutet worden, dass unsere Aufarbeitung preußischer Traditionen beunruhigt, weil sie zur Abschwächung unserer bisherigen kritischen Haltung gegenüber der preußischen Expansionspolitik nach dem Osten führen könnte. ${ }^{\text {“95 }}$ Ausführlicher registrierte Scheel das polnische Misstrauen in einer Aktennotiz aus dem selben Jahr:

„Prof. Dr. Marian Biskup, Abt.-Leiter im Historischen Institut der Polnischen Akademie der Wissenschaften, erklärte mir, dass man in Polen über die in der DDR in jüngster Zeit massiv eingesetzt habende Welle von Publikationen aller Genres, aber auch von Filmen im Fernsehen etc. beunruhigt sei, die sich mit der preußischen Geschichte beschäftigen. Man frage sich, wo das enden solle. Man begreife nicht die politische Stoßrichtung dieser Aktivitäten.

Diese Beunruhigung möge ich bitte aus polnischer Sicht verstehen, für die beispielsweise Friedrich II einer der Totengräber des selbständigen polnischen Staates war (1. poln. Teilung 1772) [...], für die Gneisenau und Clausewitz als die preußischen Militärs gelten, die 1831 den zaristischen Truppen unrühmliche Schützenhilfe bei der Niederschlagung des polnischen November-Aufstandes leisteten etc. etc. [...] Für mich war erstaunlich, dass Biskup, den ich als einen soliden Historiker kenne, der sich normalerweise nur zu Dingen äußert, die er wirklich gelesen hat und gründlich kennt, hier Vorstellungen kolportierte, die ganz offensichtlich aus oberflächlichster Optik gewonnen sind. Diese Tatsache bestärkt mich in der Annahme, dass er dieses Gespräch in irgendeinem Auftrag gesucht hat. ${ }^{\text {} 96}$

\footnotetext{
93 Antoni Czubiński, Sesja naukowa poświęcona roli Prus i reakcyjnego prusactwa w historii Niemiec [Wissenschaftliche Konferenz zur Rolle Preußens und des reaktionären Preußentums in der Geschichte Deutschlands], in: Przegląd Zachodni 26/1 (1970), S. 230-232, hier S. 232. Bei der Tagung handelte es sich um die erste ostdeutsche Historikerkonferenz zur preußischen Geschichte; vgl. Gustav Seeber, Preußen nach 1789 in der DDR-Historiographie. Entwicklungsetappen und Grundpositionen, in: Alfred Anderle (Hrsg.), Entwicklungsprobleme der marxistisch-leninistischen Geschichtswissenschaft in der UdSSR und in der DDR, Halle a. d. Saale 1983, S. 218-229, hier S. 227.

${ }^{94}$ Gerard Labuda, Projekt sesji historyków polskich i NRD na temat historii Prus [Projekt einer Tagung mit Historikern aus Polen und der DDR zur Geschichte Preußens], 18. 12. 1970, in: Archiwum PAN w Poznaniu, III-77/12, Bl. 215.

${ }_{95}$ Zum Vortrag von Dr. Jarema Maciszewski vom Juni 1980, ohne Verfasserangabe, undatiert [Juni 1980], in: ABBAW, ZIG 710/4.

${ }_{96}$ Heinrich Scheel, Aktennotiz über eine von dem Vorsitzenden der polnischen Sektion der bilateralen Historikerkommission DDR-VR Polen gewünschte persönliche Unterredung am 29.5. 80 anlässlich der 27. Tagung dieser Kommission in Leipzig, Berlin, 17.6. 1980, in: ABBAW, ZIG 710/2.
} 
Der polnischen Beunruhigung wurde Rechnung getragen. Auf Wunsch der Polen fand im Spätherbst 1980 im Posener Westinstitut ein außerordentliches wissenschaftliches Treffen beider Seiten zur Preußenfrage statt, „bei dem ohne jede Publizität ein freundschaftlicher Meinungsaustausch erfolgen sollte ${ }^{\text {997 }}$. AbschlieBend wurde festgehalten, „dass die Beratung nützlich war und zur Klärung dieser schwierigen Problematik in der VRP beigetragen hat, wenngleich - wie von der Seite der VRP zum Ausdruck gebracht wurde - noch nicht alle Vorbehalte ausgeräumt worden sind und die Kommission der Frage auch weiterhin eine bestimmte Aufmerksamkeit wird schenken müssen “98.

So wurde das Thema 1986 - erneut auf polnischen Wunsch hin - nochmals aufgegriffen, diesmal im Rahmen einer regulären Zusammenkunft der Kommission. „Dabei“, so der entsprechende Bericht, „verfolgte man die Absicht, Fachleute aus der DDR mit den Grundvorstellungen der in Poznań unter Hinzuziehung von Historikern aus Toruń vorbereiteten dreibändigen Geschichte PreuBens bekannt zu machen. “99 Offenbar ging es den polnischen Historikern also darum, die deutschen Kollegen für ihre Interpretation der preußischen Geschichte zu gewinnen. Dass dies nur unvollständig gelang, zeigte sich noch 1988 anlässlich eines Polenbesuchs von Ingo Materna, der sich im Westinstitut mit dem Vorwurf konfrontiert sah, „angesichts einer Preußenwelle in der DDR“ würden „die Ergebnisse der polnischen Geschichtswissenschaft (z. B. über PreuBen und F[riedrich] II.) [...] durch die DDR-Historiker ungenügend zur Kenntnis genommen“100. Ihren Vorwurf unterstrichen die polnischen Historiker mit einer Reihe kritischer Fragen:

„- Wie versteht sich der Abriss des Berliner Schlosses mit der Aufstellung des Denkmals Friedrich II., war das nicht eine unvorbereitete Überraschung? ...

- Deuten nicht Veröffentlichungen wie Friedrich II., Bismarck u.a. auf eine Preußenwelle in der DDR (ebenso F.II.-Ausstellung in Potsdam [...] ) ? ‘101

In ähnlichen Bahnen wie die Preußen-Rehabilitation, aber weniger publikumswirksam und von der polnischen Seite deshalb auch kaum zur Kenntnis genom-

97 Ebenda. Referenten und Diskutanten waren u. a. Horst Bartel, Walter Schmidt, Ingrid Mittenzwei, Helmut Schmitter, Antoni Czubiński und Witold Jakóbczyk.

98 Protokoll der XXVIII. Tagung 1981 in Slupsk, in: ABBAW, ZIG 710/1. Zu den Inhalten der Besprechung Jan Kosim an Piotr Łossowski, Notatka informacyjna w sprawie konferencji historyków polskich i NRD w Poznaniu oraz inauguracyjnego posiedzenia Towaryzstwa im. Jabłonowskich w Lipsku [Informationsnotiz zur Konferenz der Historiker Polens und der DDR in Posen und zur Inaugurationssitzung der Jablonowski-Gesellschaft in Leipzig], 12. 12. 1980, in: IHPAN 5/208. Ein Teil der Konferenzmaterialien wurde im Przegląd Zachoni veröffentlicht.

99 Bericht über die XXXIII. Tagung der Historikerkommission DDR-VR Polen, 24. 5. 1986, in: ABBAW, ZIG 710/2. Pikanterweise hatte man im September 1985 bereits Adelheid Simsch aus Westberlin angefragt, ob sie zur Begleitung dieser Synthese ein Semester in Posen zu verbringen bereit wäre, in: IHPAN, 5-87, Bl. 107.

${ }^{100}$ Ingo Materna, Bericht über eine Vortragsreise in die VR Polen vom 18.-20. 1. 1988, organisiert durch die Liga für Völkerfreundschaft der DDR auf Anforderung der „Gesellschaft WislaOdra“, Berlin, 22. 1. 1988, in: ABBAW, Historikergesellschaft der DDR (HG) 160.

101 Ebenda. 
men, erfolgten in der DDR bereits seit den 1960er Jahren Bestrebungen zu einer umfassenden Neubewertung der „Ostbeziehungen des deutschen Volkes in ihrer geschichtlichen Entwicklung“ - so der Titel eines umfangreichen Thesenpapiers aus dem Jahr 1963, das als Grundlage für eine Publikation zum selben Thema dienen sollte ${ }^{102}$. Schon 1956 hatten Deutsche und Polen in der Historikerkommission „gemeinsam festgestellt, dass man die Wanderung deutscher Handwerker und Bauern nach Polen nicht in den Begriff des ,Dranges nach dem Osten“ einbeziehen dürfe “103. Ein Vierteljahrhundert später (auf dem Höhepunkt der Erbeund-Traditions-Welle) attestierte Walter Schmidt diesen Bemühungen rückblickend, dass „bei einem so komplizierten historischen Vorgang wie der feudalen Ostexpansion und -kolonisation doch schon klar $\mathrm{zu}$ differenzieren versucht [wurde] zwischen dem, was progressiv war, und dem, was sich negativ und verhängnisvoll auswirkte“104. In Abwandlung der ursprünglichen pauschalen Verdammung der Ostexpansion zeigte man sich also bereits in den sechziger Jahren bemüht, dem historischen Phänomen auch positive Aspekte abzugewinnen.

Anfänglich erfolgte die Aneignung der deutschen Geschichte durch die DDRHistoriographie beinahe verstohlen, erst in den achtziger Jahren - in der Diskussion um das „Erweiterte Erbe“ - erhielt sie öffentlichen Ausdruck und offizielle Sanktionierung. Nun wurden drei „gesetzmäßige“ Phasen der historiographischen Entwicklung in der DDR betont: In den späten 1940er Jahren habe sich die DDR-Historiographie auf die Ablehnung des reaktionären Konservatismus, Imperialismus und Faschismus konzentriert, im Zeichen des konsolidierten Sozialismus der 1950er und 60er Jahre habe sich ihr Interesse dann auf alle progressiven Leistungen des deutschen Volkes ausgeweitet, um in einer dritten Etappe seit den 1970er Jahren schließlich ein neues Verhältnis zur ganzen deutschen Geschichte zu entwickeln ${ }^{105}$. Die polnischen Partner zeigten sich von solchen Horizonterweiterungen freilich wenig angetan und bezweifelten wiederholt den Nutzen des erweiterten Erbe-Begriffs ${ }^{106}$.

102 Die Ostbeziehungen des deutschen Volkes in ihrer geschichtlichen Entwicklung, undatiert [vor dem 15. 8. 1963], in: ABBAW, HG 67. Auf der Grundlage dieses Thesenpapiers sollte eine „Kurze Geschichte der Ostbeziehungen des deutschen Volkes (bzw. der deutschen Ostpolitik)“ entstehen, deren Veröffentlichung für 1964 geplant war, aus ungeklärten Gründen aber nicht zustande kam. Dr. R/K, Beantwortung des Fragespiegels, Leipzig, 7. 9. 1963, in: ABBAW, HG 160.

103 Felix-Heinrich Gentzen, Einschätzung der Forschungsarbeiten auf dem Gebiet der Geschichte Polens seit 1955, 27. 8. 1962, in: BA Berlin, SAPMO, DY 30/IV 2/9.04/98.

104 Walter Schmidt, Zur Entwicklung des Erbe- und Traditionsverständnisses in der Geschichtsschreibung der DDR, in: Zeitschrift für Geschichtswissenschaft 33/1 (1985), S. 195-212, hier S. 204.

105 Vgl. Horst Bartel/Walter Schmidt, Historisches Erbe und Tradition - Bilanz, Probleme, Konsequenzen, in: Zeitschrift für Geschichtswissenschaft 30/2 (1982), S. 816-829; Schmidt, Entwicklung des Erbe- und Traditionsverständnisses.

106 So hinterbrachte Materna seinen Kollegen 1988 etwa folgende polnische Einschätzung: „Die erweiterte Erbe-Traditionssicht führte bisher wohl nur für den Feudalismus zu Weiterungen.“ Ingo Materna, Bericht über eine Vortragsreise in die VR Polen vom 18.-20. 1. 1988, organisiert 
Doch umgekehrt wuchs auch die deutsche Irritation über die Polen. Unverkennbar legten diese bei der Herausarbeitung der gemeinsamen progressiven Traditionen beider Völker nur mäßigen Eifer an den Tag. Typisch für diesen Problembefund ist ein 1970 von Heinrich Scheel verfasstes Gutachten zum Manuskript von Antoni Czubiński über den Einfluss der deutschen Novemberrevolution von 1918 auf die Wiedererrichtung des unabhängigen polnischen Staates. Scheel schrieb:

„[Es] blieben noch einige Wünsche hinsichtlich der Einschätzung des polnischen Staates und der nationalen Bewegung offen. Wir möchten Sie bitten, diese Probleme [...] noch einmal zu überarbeiten. So halten die Gutachter für problematisch, dass die Klassenposition der verschiedenen gesellschaftlichen Kräfte nicht differenzierter herausgeschält wird. Dadurch entsteht der Eindruck, es handele sich um einen polnischen Staat, über den Klassen`.

Vielleicht wäre es möglich, stärker als bisher die Auswirkung der Novemberrevolution auf die Belebung der sozialen Kämpfe in ganz Polen und auf die Stärkung der internationalistischen Zusammenarbeit zwischen den proletarischen Zentren zu zeigen. Mit anderen Worten, gegenwärtig beschränkt sich die Darstellung noch zu sehr auf Grenzfragen, d.h. die nationale Problematik im engeren Sinne. ${ }^{107}$

Hinter dem polnischen Beharren auf nationalen Positionen stand die Erkenntnis, dass man - sollte man sich zur Anerkennung einer im marxistischen Sinne positiven Tradition in der Geschichte Polens durchringen - aufgrund der antagonistischen Konzeption dieser Lehre auch unweigerlich eine negative Tradition würde anerkennen müssen. Letztlich wäre man gezwungen gewesen, den integrativen Mythos der polnischen Nationalgeschichte zugunsten einer dialektischen Darstellung aufzugeben und damit eine Ambivalenz zuzulassen, die den von ostdeutscher Seite so eifrig betriebenen Relativierungsbemühungen in die Hände gespielt hätte. Am Ende stünde eine normative Gleichsetzung von deutscher und polnischer Geschichte, die den Polen aus naheliegenden Gründen unerträglich schien.

durch die Liga für Völkerfreundschaft der DDR auf Anforderung der „Gesellschaft WislaOdra“, Berlin, 22. 1. 1988, in: ABBAW, HG 160.

107 Heinrich Scheel an Antoni Czubiński, undatiert [September 1970], in: ABBAW, ZIG 710/5. Ähnlich in anderem Zusammenhang: „Insgesamt ist [...] zu unterstreichen, dass die nationale Frage stark betont und teilweise sehr verabsolutiert und losgelöst von der sozialen Problematik betrachtet wurde. Die Referate zur Geschichte Volkspolens fanden in der Diskussion relativ wenig Beachtung. Dagegen spielte das ,Zwischenkriegspolen“ eine viel grössere Rolle, im Grunde die zentrale Rolle, was [...] insgesamt für die polnische Geschichtswissenschaft kennzeichnend ist [...]." Walter Schmidt, Bericht über die Teilnahme am X. Allgemeinen Kongress der Polnischen Historikergesellschaft, 14. 10. 1969, in: ABBAW, HG 160. Ungeachtet ihrer eigenen Rückwendung zu Erbe und Tradition glaubte sich die deutsche Seite also weiterhin berechtigt, den Polen nationalistische Tendenzen vorzuwerfen. 


\section{Zweiter Weltkrieg}

Als Folge solcher Spannungen verschärfte sich die Kritik an der Gegenseite und ihrer - so nahm man es jeweils wahr - historiographischen Schönfärberei. Am heftigsten entbrannte diese Auseinandersetzung um den Zweiten Weltkrieg und seine Vorgeschichte ${ }^{108}$. Deutscherseits wurde dieser in den internationalen Kontext des Niedergangs des kapitalistisch-imperialistischen Systems gestellt und innenpolitisch dem Monopolkapitalismus angelastet ${ }^{109}$. Gegen diese verharmlosende Darstellungsweise erhoben die Polen scharfe Kritik. So berichtete Scheel von der 17. Tagung der deutsch-polnischen Historikerkommission im Juni 1970:

„Meinungsverschiedenheiten kamen [...] im Arbeitskreis I [...] zum Ausdruck: So z. B. im Beitrag des Sekretärs der polnischen Sektion, Professor Dr. Jędruszczak, der die uns schon bekannte These vertrat, dass der Charakter des Faschismus nicht allein vom Monopolkapitalismus her bestimmt werden könne, wie das durch die Historiker der DDR geschehe [...]. Dabei wurde in der diesmaligen Diskussion und in persönlichen Gesprächen deutlich, dass es der polnischen Seite um die Frage geht, ob mit der Erklärung des Charakters des Faschismus aus den Interessen der Monopolbourgeoisie heraus, nicht eine Einengung der Kriegsschuld eines großen Teils des deutschen Volkes nur auf die Monopolbourgeoisie erfolge. [...]

Von Jẹdruszczak und anderen wurde - auch bei dieser Gelegenheit nicht erstmalig - angedeutet, dass in unseren Darstelllungen des Faschismus die Verbrechen, wie z. B. die Okkupation Polens, an denen sehr viele Deutsche teilgenommen haben, nicht genügend berücksichtigt würden. Ebenso sind wir schon mehrmals darauf hingewiesen worden, dass der Anteil des polnischen Volkes an der Zerschlagung des deutschen Faschismus in unserer Geschichtsschreibung nicht ausreichend beachtet werde. “110

\footnotetext{
${ }^{108}$ Die DPHK widmete sich dem Thema in offiziellem Rahmen erst 1960, d. h. nachdem 1959 die deutsch-sowjetische Historikerkommission (DSHK) verbindliche Deutungsvorgaben geliefert hatte; vgl. Stelzig, Geschichtsbild, S. 257. An der einschlägigen Sitzung der DSHK in Berlin waren mit Kazimierz Popiołek und Czesław Madajczyk auch zwei polnische Historiker anwesend, die über die deutsche Besatzungspolitik in Polen referierten; vgl. Karl-Heinz Schwarze, Die Kommission der Historiker der DDR und der UdSSR, in: Hellmann (Hrsg.), Osteuropa, Bd. 1, S. 104-113, hier S. 107.

${ }^{109}$ Dabei stützte man sich auf die von Georgi Dimitroff 1935 auf dem VII. Weltkongress der kommunistischen Internationale geprägte Formel, die das NS-Regime als die „offene Diktatur der reaktionärsten Gruppe des deutschen Finanzkapitals“ definiert hatte. Sabrow, Diktat, S. 379. ${ }^{110}$ Heinrich Scheel, Bericht über die XVII. Tagung der Kommission der Historiker der DDR und der VR Polen in der Zeit vom 2. bis 5. Juni 1970 in Görlitz, 4. 6. 1970, in: BA Berlin, SAPMO, DY/30/IV A 2/9.07/160. Dass man auf polnischer Seite in einem weniger polarisierten Kontext durchaus zu einer differenzierten Behandlung der Kollektivschuldfrage bereit war, wird deutlich bei Andrzej Feliks Grabski/Czesław Madajczyk, Niemcy w historiografii Polski Ludowej [Deutschland in der Historiographie Volkspolens], in: Przegląd Zachodni 37 (1981), S. 39-55, hier S. 45 .
} 
Offenbar erkannten die polnischen Historiker, dass man sich in der DDR unter Verweis auf historische Gesetzmäßigkeiten um eine Aufarbeitung der NS-Vergangenheit drücken wollte. Doch nicht nur die Breite der Verantwortung innerhalb der deutschen Gesellschaft, sondern auch die grundsätzliche Frage nach der deutschen Kriegsschuld wurde von beiden Seiten unterschiedlich beantwortet. Davon zeugen die Kommentare, die polnische Historiker im Herbst 1968 zur Konzeption einer geplanten ostdeutschen „Geschichte Deutschlands im Zweiten Weltkrieg“ formulierten:

„Die Verfasser haben die Genesis des zweiten Weltkrieges eingehend beleuchtet. Es wäre jedoch notwendig, die Tatsache stärker zu unterstreichen, dass das 3. Reich die Verantwortung für die Entfachung des Zweiten Weltkrieges trägt. [...] Die Verfasser unterstreichen mehrmals die Notwendigkeit, die Einschätzung des Charakters des Krieges zu differenzieren, der von den einzelnen, vom III. Reich überfallenen Staaten geführt wurde. Im Zusammenhang damit möchten wir den Vorschlag machen, eindeutig zu formulieren, dass Polen vom ersten Kriegstag an einen gerechten Verteidigungskrieg geführt hat, um seine Existenz zu wahren."

Im Spiegel der polnischen Kritik tritt uns hier ein Paradebeispiel dessen entgegen, wie die Zwei-Stränge-Konzeption es gestattete, historische Verantwortung abzuschieben. Doch damit nicht genug. Bald diente die Zwei-Stränge-Konzeption nicht mehr nur dazu, Deutschland zu entschuldigen, sondern sie wurde auch dazu verwendet, Polen partiell zu beschuldigen. So wurde 1964 für eine der folgenden Tagungen der gemeinsamem Kommission „eine vergleichende Betrachtung der faschistischen Bewegung und der faschistischen staatlichen Struktur in Deutschland und Polen“ ins Auge gefasst ${ }^{112}$. Offensichtlich sperrten sich die Polen gegen diese Themenstellung, jedenfalls wurde sie später nicht mehr aufgegriffen $^{113}$. 1975 ließ Janusz Żarnowski auf einer Konferenz zum Thema „Entwicklung der Geschichtswissenschaft in der DDR und der VRP“ dann durchblicken, dass die neuere polnische Geschichtswissenschaft zu einer engeren Definition des Faschismus tendiere, in deren Rahmen der polnische Staat der 1930er Jahre keinen Platz finde ${ }^{114}$. Dem konnten sich die ostdeutschen Kollegen offenbar nicht anschließen, denn noch 1988 wurden sie von den Polen gefragt, ob „der 2. Weltkrieg in seiner 1 . Phase in der DDR immer noch beiderseitig imperialistisch charakterisiert" werde ${ }^{115}$.

111 Bemerkungen zu der Konzeption der „Geschichte Deutschlands im zweiten Weltkrieg“ (Übersetzung aus dem Polnischen), undatiert [Herbst 1968], in: ABBAW, ZIG 171.

112 Gerhard Schilfert/Kazimierz Popiołek, Schlussprotokoll der XI. Tagung der deutsch-polnischen Historikerkommission, Wernigerode, 28. 5. 1964, S. 2, in: ABBAW, ZIG 710/1.

113 Nur in seltenen Fällen kam die polnische Seite der ostdeutschen insofern entgegen, als dass sie vage den „internationalen Charakter des Faschismus und die Solidarität seiner Gegner“ anerkannte. Stelzig, Geschichtsbild, S. 252.

114 Vgl. ebenda, S. 274.

115 Bericht über eine Vortragsreise in die VR Polen vom 18.-20. 1. 1988, organisiert durch die Liga für Völkerfreundschaft der DDR auf Anforderung der „Gesellschaft Wisla-Odra“, in: ABBAW, HG 160/4. 
Offensichtlich machte sich die ostdeutsche Seite im Umgang mit dem faschistischen Erbe das tu-quoque-Argument zu eigen. Demnach war auch das Polen der späten Zwischenkriegszeit ein faschistischer Staat - seine Eroberung durch Deutschland erfolgte damit gewissermaßen im Zuge der Selbstzerfleischung der imperialistischen Mächte ${ }^{116}$. Gegen diese Tendenz zur Gleichsetzung kämpften die Polen. Zu ganz grundsätzlichen Äußerungen sah sich Czesław Madajczyk in den späten siebziger Jahren veranlasst:

„Der 1939 vom Zaun gebrochene Krieg wurde zur einzigen Möglichkeit den Hitlerfaschismus in seine Schranken zu weisen und schließlich zu vernichten. Daher war der polnisch-deutsche Feldzug so, wie er auf polnischer Seite geführt wurde, ein gerechter Krieg. " ${ }^{117}$

Es mutet rückblickend erstaunlich an, dass polnische Historiker sich genötigt sahen, den Widerstand ihres Landes gegen die deutsche Aggression von $1939 \mathrm{zu}$ verteidigen. Verständlich wird diese Konstellation bei einem Seitenblick auf die Sowjetunion. Auch diese war vor dem Hintergrund des Hitler-Stalin-Paktes daran interessiert, den polnischen Staat der späten Zwischenkriegszeit als Hort des Faschismus zu deuten, um den sowjetischen Einmarsch in Ostpolen als antifaschistischen Präventivschlag darstellen zu können.

Angesichts solcher Konstellationen war den Polen schon früh bewusst, dass ihre Sichtweise auf die deutsch-polnisch-sowjetische Beziehungsgeschichte zwischen 1917 und 1945 im „Ostblock“ nur geringe Aussichten auf Anerkennung hatte. Mochten die zwei großen Nachbarn auch im sozialistischen Gewand als neue Verbündete Polens auftreten - ihre fortdauernde historiographische Interessengemeinschaft hinsichtlich des Jahres 1939 bot jahrhundertealtem polnischem Misstrauen neue Nahrung und hielt die Erinnerung an die Gefahren der

\footnotetext{
116 Diese Argumentationsfigur - wenngleich in etwas abgemilderter Form - scheint auch in den frühen westdeutsch-polnischen Kontakten auf. So wollten die deutschen Initiatoren die erste westdeutsch-polnische Historikerbegegnung 1956 in Tübingen anfangs ganz dem Thema des deutsch-polnischen Nichtangriffsvertrags von 1934 widmen und plädierten u. a. für einen „Vergleich zwischen der Krise der Demokratie in Deutschland und Polen" in den 1930er Jahren. Ruchniewicz, Zögernde Annäherung, S. 28.

117 Czesław Madajczyk, Die internationale Bedeutung des von Polen im Jahre 1939 geführten Verteidigungskrieges, undatiert [1978 oder 1979], in: ABBAW, ZIG 710/7. Ungeachtet der Berechtigung solcher Aussagen neigten polnische Historiker bisweilen auch dazu, die Gerechtigkeit der polnischen Sache zu verabsolutieren und deren kritikwürdige Aspekte zu bemänteln. So erklärte der Parteihistoriker Jarema Maciszewski noch 1980 jegliche Beschäftigung mit der Aussiedlung und Vertreibung von Deutschen nach Kriegsende für inopportun: „Es hätte [...] nicht den geringsten Sinn und Zweck, wenn wir in Polen Monographien zur Aussiedlung von Deutschen in den Jahren 1946-47 anfertigen. [...] Es ist wohl auch nicht notwendig, bei der Darlegung der historischen Forschungsergebnisse alle, oft dramatischen Einzelheiten hervorzuheben, von denen der Kampf des polnischen Volkes gegen den Hitler-Okkupanten begleitet war, besonders der, die [...] einen falschen Eindruck vom Charakter und den Methoden unseres Kampfes hervorrufen könnte. Es war ein Kampf auf Leben und Tod ..." Übersetzung eines internen Vortrags von Prof. Jarema Maciszewski, Leiter Abt. Wissenschaft und Volksbildung im ZK [der PVAP], gehalten Mitte Juni 1980, in: ABBAW, ZIG 710/4, S. 33 f.
} 
polnischen Mittellage lebendig ${ }^{118}$. Es war daher nicht erstaunlich, dass man begann, verstärkt auch jenseits der Blockgrenzen um Sympathie für die polnische Position zu werben ${ }^{119}$. So plante die Polnische Akademie der Wissenschaften in der zweiten Hälfte der sechziger Jahre eine internationale Konferenz zu Problemen des Zweiten Weltkriegs ${ }^{120}$, die von ostdeutscher Seite pro forma unterstützt wurde $^{121}$. Gewissermaßen als letzte Solidaritätsprobe wurde das Thema 1967 auch zum Gegenstand der jährlichen Sitzung der deutsch-polnischen Historikerkommission erhoben - mit einem für beide Seiten ernüchternden, wenngleich nicht unerwarteten Ergebnis: Referate und Diskussionen offenbarten scharfe Gegensätze in der Beurteilung der Vorgeschichte des Krieges, insbesondere hinsichtlich des Versailler Systems, des Rapallo-Vertrags, der Rolle der Komintern und des Hitler-Stalin-Pakts inklusive seiner Zusatzverträge. Ein vertraulicher Bericht der ostdeutschen Seite vermerkte ${ }^{122}$ :

„Heftig angegriffen wurden [von den Polen] das geheime ,Zusatzprotokol` vom

23. 8. 1939 und die drei geheimen ,Zusatzprotokolle“ vom 28.9. 1939. In einem

118 Misstrauen gegenüber der UdSSR kam in den Sitzungen der Historikerkommission immer wieder zum Ausdruck. So „verstieg sich“ Wereszycki auf dem polnischen Historikertag 1958 „unter lebhaftem Beifall zu folgenden Feststellungen: Immer wenn Russland schwach war, war Polen stark. Nur ein Weltkrieg konnte Polen befreien, und nur ein neuer Weltkrieg wird ihm die endgültige Freiheit geben." Felix-Heinrich Gentzen, Bericht über den VII. Kongress der polnischen Historiker vom 12.-17.9.58 in Kraków, undatiert [September 1958], in: ABBAW, ZIG 710/2. Ähnlich eine ostdeutsche Einschätzung aus dem Jahr 1980: „Auch nach unseren Erfahrungen ist das [sowjetisch-polnische Verhältnis] nach wie vor das gravierende politische Problem sowohl in der polnischen Geschichtswissenschaft als auch darüber hinaus in der gesamten Selbstdarstellung des polnischen Volkes heute. Nicht zuletzt wurde das in den jüngsten politischen Vorgängen - sowohl im Hinblick auf das Auftreten Wyszyńskis als auch einiger ,Streikführer' deutlich, z. B. in der massiven Bezugnahme auf die ,Schlacht an der Weichsel' im Jahre 1920." H. Scheel/H. Gemkow/R. Jeske, Zum Vortrag von Dr. Jarema Maciszewski vom Juni 1980, undatiert, in: ABBAW, ZIG 710/4.

${ }_{119}$ Voraussetzung hierfür war die allmähliche Anerkennung der volkspolnischen Historiker als legitime Vertreter der polnischen Historiographie auf dem internationalen Parkett, insbesondere im Comité International des Sciences Historiques, wo sie sich erst in den 1960er Jahren endgültig gegen die Konkurrenz der exilpolnischen Geschichtsforscher durchsetzen konnten.

${ }^{120}$ Dazu hatten Historiker aus der Tschechoslowakei, Frankreich, der Bundesrepublik Deutschland, Ungarn und der UdSSR ihre Teilnahme zugesagt. Tadeusz Manteuffel an das Institut für Geschichte der Akademie der Wissenschaften der DDR, Warschau, 19.4. 1967, in: ABBAW, ZIG 710/1. Die Konferenz war zunächst für 1967 geplant, wurde dann aber auf 1970 vertagt. Schilfert/Ryszka, Beschlussprotokoll der XIV. Tagung der Kommission 1967 in Augustow, 19. 5. 1967, in: Ebenda.

121 „Die DDR-Seite unterstützt die von der polnischen Akademie der Wissenschaften für 1970/ 71 geplante internationale Konferenz in Warszawa zu Problemen des II. Weltkrieges." Beschlussprotokoll der XVI. Tagung der Kommission 1969 in Myszkowce, in: Ebenda.

${ }_{122}$ Eildermann/Löwel, Bericht über die Tagung der deutsch-polnischen Historikerkommission vom 17.-19. Mai 1967 in Augustow, undatiert [Sommer 1967], in: ABBAW, ZIG 555. In der DDR wurde das geheime Zusatzprotokoll zum Hitler-Stalin-Pakt bis 1989 geleugnet. Der einzige diesbezügliche Tabubruch, der jedoch umgehend geahndet wurde, findet sich bei Günter Paulus, Die zwölf Jahre des Tausendjährigen Reiches, Berlin 1965. Vgl. dazu Sabrow, Diktat, S. 378393, insbesondere S. 382. 
der letztgenannten ,Zusatzprotokolle‘, die Dozent Wojciechowski im Bonner Archiv eingesehen hat, soll u. a. eine Vereinbarung über gegenseitige Information und Zusammenarbeit bei der Bekämpfung der polnischen Widerstandsbewegung enthalten sein. Auf dieser Grundlage sei es zu zwei Treffen von Vertretern der Gestapo und des NKWD gekommen. In diesem Zusammenhang machte eine polnische Genossin vom Archiv des Instituts für Parteigeschichte in Warszawa in einer Pause zu Prof. Eildermann die Bemerkung, dass es ein Material gebe, nach dem das NKWD der Gestapo 500 deutsche Kommunisten übergeben habe. “123

Beide Parteien schieden in der Gewissheit, sich auf dem internationalen Parkett nicht auf die Solidarität der anderen Seite verlassen zu können. Deutscherseits notierte Eildermann im Hinblick auf die internationale Konferenz misstrauisch:

„Trotzdem die polnischen Freunde versicherten, dass sie die genannten Probleme in der internationalen Beratung, an der auch westdeutsche Historiker teilnehmen werden, nicht aufwerfen wollen, sind wir dennoch davon überzeugt, dass sie zur Sprache kommen werden. Bei den unterschiedlichen Standpunkten wird deshalb ein gemeinsames einheitliches Auftreten nicht gesichert sein können. “124

\section{Erreichtes und Versäumtes}

\section{Seitenblick auf die Bundesrepublik}

In der Folge gelang mit dem Warschauer Vertrag vom 7. Dezember 1970 rascher als erwartet der politische Durchbruch in den Beziehungen zwischen der Bundesrepublik und der Volksrepublik Polen. In seinem Umfeld intensivierten sich auch die sporadischen Kontakte zwischen westdeutschen und volkspolnischen Historikern. Besorgt rapportierte H. Lehmann 1970 von seiner Konferenzteilnahme in Posen, „dass es einige polnische Historiker gibt, die der kämpferischen Auseinandersetzung mit der westdeutschen Geschichtsschreibung nicht zustimmen, sondern ein kollegiales Verhältnis zu den bürgerlichen, ebenso wie zu den sozialistischen Historikern aufrecht erhalten möchten “125. Bereits 1972 traten die Beziehungen zu den westdeutschen Historikern dann in den Vordergrund: Unter dem Dach der deutsch-polnischen Schulbuchkommission fanden sie zu einer institutionalisierten, kontinuierlichen Form ${ }^{126}$. Schon Ende des Jahres urteilte das pol-

123 Eildermann, Bericht über die Tagung der deutsch-polnischen Historikerkommission vom 17.-19. Mai 1967 in Augustow, in: ABBAW, ZIG 555.

124 Ebenda.

125 H. Lehmann, [Reisebericht über Teilnahme an Konferenz in Poznan], 14. 10. 1970, in: ABBAW, ZIG 171.

${ }^{126}$ Vgl. Klaus Zernack, Zwanzig Jahre danach, in: Gemeinsame Deutsch-Polnische Schulbuchkommission (Hrsg.), Empfehlungen für die Schulbücher der Geschichte und Geographie in der Bundesrepublik Deutschland und in der Volksrepublik Polen, Braunschweig 1995, S. 5-12, sowie Thomas Strobel, Die Gemeinsame deutsch-polnische Schulbuchkommission. Ein spezifi- 
nische Außenministerium: „Die Zusammenarbeit und der wissenschaftliche Austausch mit der Bundesrepublik Deutschland ist konkreter und nützlicher als jener mit der DDR.“" ${ }^{127}$

Waren die Themen der Schulbuchkommission oftmals auch ganz ähnlich gewählt wie jene der ostdeutsch-polnischen Kommission ${ }^{128}$, so übertrafen ihre Erträge doch rasch alles, was das ostdeutsch-polnische Pendant nach fünfzehn Jahren Vorsprung aufzuweisen hatte. Regelmäßig wurden die Materialien der wissenschaftlichen Sitzungen publiziert, und bereits 1976 konnten umfassende gemeinsame Schulbuchempfehlungen verabschiedet werden. Zudem wurde der westdeutsch-polnischen Kommission eine wesentlich größere Publizität zuteil als ihrer Ostblock-Schwester. 1975 zog Marian Wojciechowski im Parteiorgan Nowe drogi denn auch eine überwiegend positive Bilanz der bisherigen Aussprachen mit den bundesdeutschen Fachkollegen. Selbst in heiklen Fragen wie der polnischen Staatswerdung, der deutschen Ostkolonisation, der Teilungen Polens und seiner Wiederherstellung 1918 habe man eine gemeinsame Sichtweise finden können. Einzig in der Bewertung des Ordensstaates bestünden noch Differenzen; andererseits seien die Gespräche über Nationalsozialismus, Zweiten Weltkrieg und deutsche Okkupationspolitik in Polen „über Erwarten glatt“ verlaufen. Zu wünschen übrig lasse noch die Umsetzung der Empfehlungen in den föderalen Strukturen der BRD, während in polnischen Schulbüchern grundlegende Anpassungen stattgefunden hätten: „Es ist kaum vorstellbar, dass irgendwer in der polnischen Schule heute die Problematik BRD nach der gleichen Art wie vor Abschluss des Vertrages vom 7. Dezember 1970 unterrichten würde." Der letzte Satz schien bei den abseits stehenden ostdeutschen Historikern besonderes Missfallen zu erregen, jedenfalls ist er in einer Rohübersetzung des Artikels in den Akten der DDR-Sektion mit Randanstreichungen versehen worden ${ }^{129}$.

Überhaupt stieß die westdeutsch-polnische Annäherung bei den ostdeutschen Eliten rundweg auf Ablehnung, stellte sie doch nachgerade die Legitimation der

scher Beitrag zur Ost-West-Verständigung 1972-1989, in: Archiv für Sozialgeschichte 45 (2005), S. 253-268.

127 J. Stępień, Notatka z narady w Departamencie Współpracy Kulturalnej i Naukowej MSZ w dniu 13 listopada 1972 roku poświęconej problematyce współpracy naukowej pomiędzy Polską i Niemiecka̧ Republika̧ Federalna̧ [Notiz zur Besprechung im Departement für kulturelle und wissenschaftliche Zusammenarbeit beim Ministerium für Auswärtige Angelegenheiten...], 13. 11. 1972, in: Archiwum Ministerstwa Spraw Zagranicznych, Warschau, D IV 46/77, W-13, t-1. 128 U. a. wurden thematisiert: die Rolle Schlesiens und Pommerns sowie des Deutschen Ordens für die deutsch-polnischen Beziehungen, Aufklärung, Vormärz und Völkerfrühling, Industrialisierung und Arbeiterbewegung in Deutschland und Polen, die Bedeutung der Nationalgeschichte in beiden Staaten, deutsch-polnische Beziehungen 1919-1932, 1945-1975, deutsche und polnische Widerstandsbewegung im Zweiten Weltkrieg; vgl. Olszewski, Die deutsche Historiographie über Polen aus polnischer Sicht, in: Dahlmann (Hrsg.), Hundert Jahre Osteuropäische Geschichte, S. 290.

129 Marian Wojciechowski, Z prac komisji podrȩcznikowej PRL-RFN [Aus der Arbeit der Kommission für Schullehrbücher Polen - BRD], in: Nowe drogi 9 (316), Warschau, September 1975, S. 132-141, zit. nach der deutschen Übersetzung für die DDR-Sektion der Historikerkommission von Władysław Markiewicz, in: ABBAW, ZIG 710/2. 
DDR als das bessere, antifaschistische und daher einzig legitime Deutschland in Frage. Die SED hatte sich ihre Loyalität zur Oder-Neiße-Grenze bislang damit vergelten lassen, dass die polnische Seite die DDR in der internationalen Arena gegenüber der BRD bevorzugte ${ }^{130}$. Diese Dividende drohte nun hinfällig zu werden, und die DDR lief Gefahr, den Polen angesichts der bundesdeutschen Defacto-Anerkennung der polnischen Westgrenze verzichtbar $\mathrm{zu}$ werden. Diese Option bekamen bald auch die ostdeutschen Historiker zu spüren, zeigte man ihnen in Polen doch zunehmend die kalte Schulter. So rapportierte etwa Müller Mertens 1971 nach einem lange geplanten Arbeitsbesuch in Thorn gekränkt die Abwesenheit aller Ansprechpartner vor Ort: „Prof. Gorski war nach Westdeutschland [...] gereist, Prof. Biskup fuhr zu einer Sitzung nach Warschau, auch Prof. Grudczinski weilte außerhalb." Umso mehr ärgerte Müller Mertens der unverhohlen vorgebrachte Wunsch seiner polnischen Gesprächspartner nach einer weiteren Intensivierung der Wissenschaftsbeziehungen zu Westdeutschland. „Das Interesse daran wurde nachhaltig bekundet. Umso mehr befremdete die Aufnahme des Gastes aus der DDR. “131 Ähnliches Desinteresse mussten die ostdeutschen Historiker in Polen fortan immer wieder hinnehmen ${ }^{132}$.

\section{Schulbuchfrage}

Angesichts solcher Brüskierungen entsteht der Eindruck, die polnische Seite habe die DDR in ihrem Selbstverständnis als das „bessere Deutschland“ unter Zugzwang setzen wollen ${ }^{133}$. Tatsächlich war dieser Strategie ein gewisser Erfolg

130 Vgl. Włodzimierz Borodziej/Klaus Ziemer (Hrsg.), Deutsch-polnische Beziehungen 1939_ 1945-1949. Eine Einführung, Osnabrück 2000, S. 279.

131 Müller Mertens an das Direktorat für Internationale Beziehungen der Humboldt-Universität zu Berlin, Bericht über die Vortragsreise in die VR Polen vom 1. bis 4. 6. 1971 (Abschrift), Berlin, 10.6. 1971, in: ABBAW, HG 160. Der Wahrnehmung Mertens' entsprach komplementär die selbstgefällige Beobachtung von Gotthold Rhode: „Nach wie vor betrachtet man die Deutschen aus der Bundesrepublik als die ,richtigen“ Vertreter Deutschlands." Gotthold Rhode, Kurzbericht über meine Reise durch Polen im Anschluss an die internationale Schulbuchkonferenz vom 22.-26. Februar 1972, undatiert, in: BA Koblenz, N 1445/140.

132 Dies verdeutlicht ein Bericht von der 32. Tagung der DPHK: „Auffallend war, daß an dem wissenschaftlichen Kolloquium von Angehörigen des historischen Instituts der Universität in Wrocław, in deren Räumen die Tagung stattfand, kaum jemand zu sehen war. Ob es sich dabei um eine politische Demonstration gegenüber dem Thema des wissenschaftlichen Kolloquiums gehandelt hat [sc.: „Die sozialen und kulturellen Umwälzungen in der sowjetischen Besatzungszone Deutschlands und in der Volksrepublik 1944/45 bis 1949], sei dahingestellt; von einigen polnischen Delegationsmitgliedern wurde diese Meinung geäußert. " Helmut Bleiber, Bericht über die 32. Tagung der Historiker-Kommission der DDR und der VRP vom 16. bis 21. 9. 1985 in Wrocław, undatiert, in: ABBAW, ZIG 710/2.

133 Ähnlichen taktischen Überlegungen dürfte es indes auch geschuldet sein, wenn volkspolnische Historiker im Kontakt mit westdeutschen Kollegen umgekehrt ihre starke Verbundenheit mit der ostdeutschen Historiographie herausstrichen. So betonte etwa Czubiński 1980 vor der Gemeinsamen Schulbuchkommission BRD-VRP, dass den polnischen Historikern „die von der Historiographie der DDR präsentierte Auffassung [der deutschen Geschichte] näher ist [als jene der BRD-Historiker]." Antoni Czubiński, Die Konzeption eines polnischen Lehrbuchs der deutschen Geschichte, in: Wolfgang Jacobmeyer (Hrsg.), Nationalgeschichte als Problem der 
beschieden, signalisierte die ostdeutsche Seite in der Folge doch vermehrt Verständigungsbereitschaft. Zwar lehnte sie dreiseitige Schulbuchgespräche unter Einschluss westdeutscher Historiker weiterhin kategorisch $\mathrm{ab}^{134}$, immerhin fand sie sich aber zur Wiederaufnahme der seit 1956 stockenden Schulbuchrevision im bilateralen Rahmen bereit. 1971 wurde fast zeitgleich mit der Aufnahme der westdeutsch-polnischen Gespräche eine „gemischte Kommission zwischen DDR und VRP zur Prüfung der Geschichts- und Geographie-Lehrbücher“ der jeweils anderen Seite berufen ${ }^{135}$. Zum ersten Treffen der Kommission kam es im Juni 1971 in der DDR $^{136}$. Anschließend legten beide Delegationen schriftliche Kommentare zu den Lehrbüchern der Gegenseite vor. Darin monierten die Polen die allgemeine Dürftigkeit polnischer Bezüge in den ostdeutschen Lehrmitteln. Positiv erschien ihnen, dass der Imperialismus der deutschen Herrscherklassen in allen Epochen gebührend verurteilt werde, negativ wurde vermerkt, dass der polnische Freiheitskampf (1863, 1918 ff., 1939-1945) zuwenig Beachtung fände; auch würden die Leistungen der polnischen Kultur kaum gewürdigt. Umgekehrt attestierten die deutschen Gutachter den polnischen Schulbüchern eine im Allgemeinen angemessene Darstellung der ostdeutsch-polnischen Beziehungen. Allerdings würden bisweilen die historischen Gesetzmäßigkeiten und der Klassencharakter der antipolnischen Politik Deutschlands vernachlässigt, ebenso der Zusammenhang von sozialem und nationalem Befreiungskampf ${ }^{137}$. Damit wurde einmal mehr der polnische Boykott der Zwei-Linien-Interpretation der deutschen Geschichte gerügt. In den folgenden Jahren wurden diese Schulbuchgespräche zwar fortgesetzt, sie zeitigten aber keine greifbaren Ergebnisse ${ }^{138}$.

deutschen und der polnischen Geschichtsschreibung. XV. deutsch-polnische Schulbuchkonferenz der Historiker 1982 in Braunschweig, Braunschweig 1983, S. 95-106, hier S. 101.

134 So im Rahmen der Kommissionstagungen von 1956 und 1962.

135 In auffallender Parallele zur Konstellation im Umfeld der Kommissionsgründung von 1956 ist hier wiederum das Bestreben ersichtlich, einer westdeutsch-polnischen Verständigung zuvorzukommen.

${ }^{136}$ Beteiligt waren von deutscher Seite u. a. Friedrich Weitendorf und Reinhold Kruppe, von polnischer Seite Benedykt Zientara, Marian Wojciechowski und Janusz Żarnowski. Benedykt Zientara, Uwagi dotyczaçe spraw polskich w podrȩcznikach historii w NRD [Bemerkungen zu den polnischen Bezügen in den Lehrbüchern der DDR], in: APAN-W, III-329/163.

137 So pochten die deutschen Gutachter auf den progressiven Charakter der „Befreiungskriege“ gegen Napoleon, wobei sie die sowjetischen Historiker auf ihrer Seite wussten: 1963 hatte die DSHK den antinapoleonischen Kampf ausdrücklich als progressive Gemeinsamkeit der deutschen und der russischen Politik hervorgehoben. Schwarze, Kommission der Historiker der DDR und der UdSSR, in: Hellmann (Hrsg.), Osteuropa, Bd. 1, S. 108 f. In Polen galt Napoleon indes als Vorkämpfer der nationalen Befreiung.

138 Diese Einschätzung wird durch eine parteiamtliche polnische Notiz zum Stand der polnischen Bemühungen um internationale Schulbuchrevision bestätigt. Dort werden zur DDR im Gegensatz zu nahezu allen übrigen Staaten - keine Fortschritte verzeichnet, sondern nur die Tatsache sporadischer Treffen vermerkt. Notatka o stanie prac nad weryfikacją wiedzy o Polsce w zagranicznych podreçznikach szkolnych historii i geografii [Notiz zum Stand der Arbeiten zur Prüfung des über Polen vermittelten Wissens in den ausländischen Schulbüchern der Geschichte und Geographie], undatiert [ca. 1977], in: Archiwum Akt Nowych w Warszawie (künftig: AAN), KC PZPR 1354, LVIII/532, Bl. 104-129, hier Bl. 111. 
Vor dem Hintergrund der westdeutsch-polnischen Gespräche, die 1976 umfassende gemeinsame Empfehlungen für den Geschichtsunterricht erbrachten, nimmt sich der Leistungsausweis der ostdeutsch-polnischen Verhandlungen umso bescheidener aus. Gerard Labuda beklagte rückblickend, dass es während der gesamten Wirkungszeit der Kommission nicht gelungen sei, ein wirkliches ostdeutsch-polnisches Pendant zur Schulbuchkommission der BRD und der VRP zu schaffen. Meinungsverschiedenheiten in der Beurteilung von Enno Meyers Thesen zwischen ihm und Schilfert hätten gar zu seinem Ausschluss aus der Kommission geführt. Mehrfach habe er später als Gast der DPHK im Gespräch mit Heinrich Scheel weitere Vorstöße in diese Richtung unternommen, allerdings vergeblich. Die DDR-Historiker hätten es vorgezogen, „Beobachter unserer Gespräche mit den bundesdeutschen Historikern zu bleiben “139.

Tatsächlich verfolgte die ostdeutsche Seite die Tätigkeit der Schulbuchkommission offenbar mit größerem Eifer als ihre eigenen Gespräche mit den polnischen Partnern. Davon zeugt der Umstand, dass auf „Fragen der Schulbuchrevision zwischen der Volksrepublik Polen und der BRD“ mehrere Spezialisten angesetzt wurden ${ }^{140}$. Auch ließ sich die ostdeutsche Seite in der DPHK von den polnischen Kollegen regelmäßig über die Beratungen der Schulbuchkommission informieren und versuchte über jene gar Einfluss auf deren Entscheidungsfindung zu nehmen. Das Protokoll der 36. gemeinsamen Tagung aus dem Jahr 1989 vermerkte dazu etwa Folgendes:

„Die polnische Seite informierte darüber, dass unter Federführung des Instituts Zachodni, Poznań, und des Schulbuchinstituts, Braunschweig/BRD, das Projekt einer Geschichte der deutsch-polnischen Beziehungen als Gemeinschaftsarbeit in Angriff genommen werden soll. Von uns wurde die polnische Seite gebeten, für den Fall, dass diese Arbeit auch die Zeit nach 1945 einschließen soll, darauf zu achten, dass eventuellen gesamtdeutschen Ansprüchen seitens der BRD entgegengetreten und die qualitativ neue Seite, die in der Geschichte deutsch-polnischer Beziehungen durch die Politik der DDR geschrieben wurde, gebührend beachtet wird." ${ }^{141}$

Eine eigene Beteiligung an dreiseitigen Gesprächen lehnte die DDR-Seite aber stets entrüstet $\mathrm{ab}^{142}$. Als etwa die polnische Seite 1979 eine Arbeitstagung in Poz-

\footnotetext{
139 Gerard Labuda, Rozmowy podręcznikowe: 1956-1990 [Schulbuchgespräche: 1956-1990], in: Ders. (Hrsg.), Rozmowy polsko-niemieckie, S. 461-464.

${ }^{140}$ Die Quelle nennt „Prof. Dr. Rudolf Hub, Leiter der Forschungsgruppe Schulbuchanalyse in kapitalistischen Ländern an der PH Erfurt, Direktor der Sektion Marxismus/Leninismus und Studienrat Rudolf Beyer, Arbeitsstelle für Auslandspädagogik der APW“. G. Neuner, Präsident der Akademie der Pädagogischen Wissenschaften der Deutschen Demokratischen Republik, an H. Scheel, Vizepräsident der Akademie der Wissenschaften der DDR, Berlin, 6. 8. 1979, in: ABBAW, ZIG 710/2.

${ }^{141}$ Helmut Bleiber, Bericht über die XXXVI. Tagung der Historikerkommission der Deutschen Demokratischen Republik und der Volksrepublik Polen, [Anfang Juni] 1989, in: Ebenda.

${ }^{142}$ Von dieser Verweigerungshaltung war sie nur 1956 kurz abgewichen. Damals hatte das Schlussprotokoll der zweiten Sitzung der DPHK festgehalten: „Auf Grund der Besprechung
} 
nań unter Beteiligung von VRP, DDR und BRD zum polnischen Projekt einer dreibändigen Geschichte Deutschlands vorschlug, wies Johannes Kalisch dies als „politische Instinktlosigkeit unserer polnischen Freunde“ zurück $^{143}$.

\section{Gemeinschaftsprojekte}

Die gemeinsame Kommissionsarbeit der ostdeutschen und polnischen Historiker trug ihrerseits über lange Jahre nur sehr vereinzelte Früchte. Im Laufe eines Vierteljahrhunderts waren lediglich drei Bände zur Oder-Neiße-Grenze (1959), zu den polnisch-sächsischen Beziehungen während des Nordischen Krieges (1962) und zum Ostmarkenverein (1966), sowie eine Quellenpublikation zur deutschpolnischen Freundschaft im Völkerfrühling (1982) erschienen ${ }^{144}$. Hinzu kam die gegenseitige Begutachtung historischer Standardwerke mit beziehungsgeschichtlichen Aspekten, darunter ein polnisches Gutachten zur Konzeption der Geschichte Deutschlands im Zweiten Weltkrieg ${ }^{145}$ und deutsche Gutachten zu

der Thesen von E. Meyer ,Über die Darstellung der deutsch-polnischen Beziehungen im Geschichtsunterricht' gibt die Kommission dem Wunsch Ausdruck, daß die deutschen Freunde eine geeignete Form finden für eine Besprechung der Schulbücher der DDR, der Bundesrepublik und Polens durch interessierte Fachvertreter der drei Staaten in Berlin, insbesondere auch auf der Grundlage von Rezensionen der Thesen in den historischen Zeitschriften der DDR und Polens." Die Formulierung dieses Passus lässt freilich erkennen, dass er auf polnische Anregung entstanden war. Kuczynski/Leśnodorski, Schlussprotokoll der 2. Tagung der deutsch-polnischen Historikerkommission, Berlin, 17. 11. 1956, in: ABBAW, ZIG 555. Dass die DDR-Seite dieser Formulierung zustimmte, war offenbar ein verspäteter Nachhall des 1953 eingeleiteten Bemühens um ein „gesamtdeutsches Gespräch“, das allerdings bereits im Frühjahr 1955 mit dem „Beschluss zur Verbesserung der Forschung und Lehre in der Geschichtswissenschaft der DDR“ wieder beendet worden war. Günther Heydemann, Geschichtswissenschaft im geteilten Deutschland. Entwicklungsgeschichte, Organisationsstruktur, Funktionen, Theorie- und Methodenprobleme in der Bundesrepublik Deutschland und in der DDR, Frankfurt a. M. 1980, S. 153.

${ }^{143}$ Johannes Kalisch an Heinrich Scheel, Rostock, 6. 3. 1979, in: ABBAW, ZIG 710/2. Auf dem Brief Scheels handschriftliche Antwort: „Teilnahme klar und höflich ablehnen.“

${ }^{144}$ Vgl. Goguel (Hrsg.), Polen, Deutschland; Johannes Kalisch/Jozef Gierowski (Hrsg.), Um die polnische Krone. Sachsen und Polen während des Nordischen Krieges 1700-1721, Berlin 1962; Adam Galos/Felix-Heinrich Gentzen/Witold Jakóbczyk, Die Hakatisten. Der Deutsche Ostmarkenverein (1894-1934). Ein Beitrag zur Geschichte der Ostpolitik des deutschen Imperialismus, Berlin 1966; Helmut Bleiber/Jan Kosim (Hrsg.), Dokumente zur Geschichte der deutschpolnischen Freundschaft 1830-1832, Berlin 1982. Geplant als Doppelausgabe in beiden Sprachen, aber schließlich nur polnisch erschienen: Heinrich Gemkow, Wspólne tradycje. Współdziałanie polskiego i niemieckiego ruchu robotniczego. Wybór dokumentów i materialów [Gemeinsame Traditionen. Die Zusammenarbeit der polnischen und der deutschen Arbeiterbewegung. Eine Auswahl von Dokumenten und Materialien], Warschau 1983. In deutscher Sprache blieb es bei einem schmalen Bändchen; ders, Treue Freunde - gute Nachbarn. Gemeinsame Traditionen der revolutionären deutschen und polnischen Arbeiterbewegung von den Anfängen bis zur Gegenwart, Berlin 1974.

145 Anlage zu: Bericht über die Dienstreise von Dr. Gerhard Hass, Leiter der Arbeitsgruppe Faschismus und zweiter Weltkrieg, und Dr. Olaf Groehler nach Warschau vom 4.-8. November 1968, Berlin, 13. 11. 1968, in: ABBAW, ZIG 171. 
polnischen Darstellungen der Geschichte Pommerns ${ }^{146}$, Schlesiens ${ }^{147}$ und PreuBens. Seit Ende der siebziger Jahre gab es allerdings eine merkliche Belebung einschlägiger Publikationen in der DDR. Den Rahmen hierfür boten die Studien zur Geschichte der deutsch-polnischen Beziehungen, die zwischen 1976 und 1989 in 15 Bänden bei der historischen Abteilung der Universität Leipzig erschienen und teilweise eng an die deutsch-polnische Historikerkommission angelehnt waren. Bereits der Zeitrahmen der Publikationsinitiative verdeutlicht, dass es sich hierbei um den Versuch handelte, ein Gegengewicht zur westdeutsch-polnischen Schulbuchkommission und ihren regelmäßig erscheinenden Tagungsbänden zu schaffen. Die Themen der Bände umfassten neben der unausweichlichen Beschäftigung mit dem deutschen „Imperialismus“ und dem ebenso obligaten Lob für die Freundschaftstraditionen zwischen den beiden Völkern und ihrer Vollendung in den Beziehungen zwischen der DDR und der Volksrepublik Polen auch einige unpolemisch formulierte und durchaus interessante Fragestellungen. So fanden die deutsch-polnischen Beziehungen im Zeichen der Reformation sowie im 17. und 18. Jahrhundert Behandlung, weiter Polens staatliche Restitution und Entwicklung in der Zwischenkriegszeit und die damit verbundenen Grenz- und Minderheitenfragen im deutsch-polnischen Kontext, schließlich die deutsche Ostpolitik zwischen den Weltkriegen und Polens Schicksal im Zweiten Weltkrieg ${ }^{148}$.

Demonstrativer Höhepunkt der Kommissionstätigkeit war 1981 die Herausgabe eines Bandes des Jahrbuchs für Geschichte mit Beiträgen polnischer Historiker und einer Nummer des Kwartalnik Historyczny mit Beiträgen ostdeutscher Geschichtsforscher ${ }^{149}$. Das Austauschprojekt sollte „die Wertigkeit der beiderseitigen Kooperation bekräftigen“ - einmal mehr „auch gegenüber Dritten, die westlich der Elbe beachtliche Aktivitäten in dieser Hinsicht entwickeln “150. Allerdings kam das Vorhaben schon in seiner Anlage eher einem Aneinander-Vorbeireden gleich als einem Dialog. Hinzu traten inhaltliche Differenzen: So fand die polnische Seite die deutschen Beiträge „insgesamt sehr theoretisch" ${ }^{\text {"151 }}$, wohingegen die deutsche Seite bei den polnischen Kollegen in mehreren Fällen die politische Linientreue vermisste. Konnten in den Beiträgen von Tazbir und Jȩdruszczak „die prekärsten Stellen“ noch durch übersetzerische Freiheiten gemildert werden, so sorgte der Aufsatz von Madajczyk in Ostberlin für schlaflose Nächte:

„Es ist dies nämlich ein Referat, das M. in Moskau gehalten hat und das dort

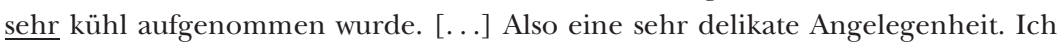

\footnotetext{
146 Jozef Gajek an das Staatssekretariat für Hoch- u. Fachschulwesen Berlin, Stettin, 1. 2. 1960, in: ABBAW, ZIG 555, sowie die Anlagen zu: Abschrift von Gerard Labuda an Johannes Schildhauer, Posen, September 1968, in: ABBAW, ZIG 710/4.

147 Zusatzprotokoll betr. Geschichte Schlesiens, 15. 11. 1956, in: ABBAW, ZIG 555.

148 Vgl. Studien zur Geschichte der deutsch-polnischen Beziehungen, hrsg. von der Sektion Geschichte der Wilhelm-Pieck-Universität Rostock, 15 Bde, Rostock 1976-1989.

149 Vgl. Jahrbuch für Geschichte 23 (1981); Kwartalnik Historyczny 88/1 (1981).

150 Vgl. Heinrich Scheel an Kurt Zeisler, Cheflektor des Akademie-Verlages, Berlin, 6. 6. 1980, in: ABBAW, ZIG 710/2.

151 Wolfgang Schröder an Heinrich Scheel, Leipzig, 3. 3. 1980, in: Ebenda.
} 
sah mein Heil nur darin, [...] dem Vielbeschäftigten in der 2. Audienz einige Änderungsvorschläge zu präsentieren, die die schlimmsten Blüten köpfen. Den Versuch zu wagen, den Stier bei den Hörnern zu packen und z. B. eine Passage vorzuschlagen, die die Verantwortung Polens an der Entwicklung der internationalen Krise von 1938/39 betrifft, hätte eine Konfrontation bedeutet, die die Kompromissbereitschaft des Autors beseitigt hätte. Vielleicht ist die vereinbarte Fassung gerade noch tragbar. Wenn man dabei berücksichtigt, dass M. offenbar mit dem Auftrag Direktor geworden war, die Zeitgeschichte zu organisieren ... “152

Pikanterweise war es in den letzten Jahren der DPHK dann aber nochmals Madajczyk, der die magere Publikationsliste der Kommission aufbesserte. 1987 wurde seine grundlegende Studie zur nationalsozialistischen Besatzungspolitik in Polen in deutscher Übersetzung in der DDR veröffentlicht ${ }^{153}$. Begründet wurde dieser Schritt mit der „Gefahr, dass ein BRD-Verlag das Buch in deutscher Sprache druckt, wenn wir es nicht übersetzen “154. Offenbar wirkte auch hier der Konkurrenzdruck von Seiten der Bundesrepublik.

Ansonsten blieben Übersetzungen insbesondere polnischer Titel ins Deutsche spärlich. Die Herausgabe einer Geschichte Polens aus polnischer Feder für deutsche Leser war ein jahrzehntelang gehegter und niemals realisierter Plan. Wurden die Erträge der wissenschaftlichen Tagungen publiziert, so geschah dies mit Ausnahme einiger Abdrucke im Jahrbuch für Geschichte - meist an relativ entlegener Stelle ${ }^{155}$. Weitgehend unerfüllt blieben damit polnische Hoffnungen, die Kommission könne der polnischen Geschichtswissenschaft ein Fenster zur deutschsprachigen Fachgemeinschaft auch jenseits der DDR aufstoßen. Weder bei der Übertragung polnischer Werke ins Deutsche noch bei der Beschaffung westdeutscher historischer Literatur - um die die polnische Seite ihre ostdeutschen Kollegen gelegentlich bat - war die Kommission sonderlich aktiv. Beides sollte ab 1972 die westdeutsch-polnische Schulbuchkommission bieten.

\section{Geschichte und Politik}

Auf der Suche nach den Gründen für die Versäumnisse der Kommission darf ein letzter Punkt nicht unbeachtet bleiben. Jenseits aller historiographischen Differenzen schürten die unberechenbaren tagespolitischen Entwicklungen in Polen ostdeutsches Misstrauen. DDR-Historiker witterten im Umgang mit polnischen

\footnotetext{
152 Ebenda. Hervorhebung im Original. Die abschließenden Auslassungspunkte stammen ebenfalls vom Autor und sind wohl als Äquivalenz eines Kopfschüttelns zu lesen.

153 Vgl. Czesław Madajczyk, Die Okkupationspolitik Nazideutschlands in Polen 1939-1945, Berlin 1987.

154 Heinrich Scheel an Otto Reinhold, Rektor der Akademie für Gesellschaftswissenschaften beim ZK der SED, Berlin, 12. 10. 1977, in: ABBAW, ZIG 710/2. Tatsächlich erschien die deutsche Übersetzung unter demselben Titel und im gleichen Umfang ein Jahr später auch in der Bundesrepublik (Köln 1988).

155 Eine Übersicht der bis 1972 erschienenen Zeitschriftenartikel zur Kommission erschließt Rautenberg, Historikerkommission, in: Hellmann (Hrsg.), Osteuropa, Bd. 1.
} 
Kollegen und auf Dienstreisen in die Volksrepublik immer wieder politische Gefahren. 1958 verband Scheel die Überlegung, polnische Gastprofessoren an ostdeutsche Universitäten einzuladen, mit Bedenken, dass diese „dann bei uns Lektionen halten, die nicht in Ordnung sind“, und entwickelte Ideen, wie man „diesem schädlichen Einfluss“ begegnen könne - nämlich „durch kritische Auseinandersetzungen im Anschluss an die Lektion“ und durch sorgfältige Auswahl der Gäste ${ }^{156}$.

Trotz solcher Vorsichtsmaßnahmen mochte sich die politische Führung in Ostberlin nicht gänzlich auf die Selbstkontrolle ihrer intellektuellen Eliten verlassen. Unter dem Eindruck der polnischen und tschechoslowakischen Protestbewegungen von 1968 wurden die universitären Kontakte der DDR in die benachbarten Volksdemokratien auf ein Mindestmaß zurückgestutzt. 1970 musste Heinrich Scheel vermelden, dass „es kaum noch Historiker bei uns gibt, die sich mit der polnischen Geschichte beschäftigen “157. Die wenigen sprachkundigen Fachkollegen hätten „im Zuge der Hochschulreform alle - oder fast alle - andere Aufgaben erhalten“158. Ein weiterer Bericht aus dem Jahr 1972 gab zu bedenken, dass der gemeinsamen Historikerkommission seit der Auflösung des Instituts für Geschichte der europäischen Volksdemokratien in Leipzig das „Hinterland“ fehle $^{159}$. Behrends Begründung für die Schließung dieses Instituts darf daher analog auch für die fachliche Austrocknung der deutsch-polnischen Historikerkommission (und ihrer deutsch-tschechischen Schwester) gelten: „Damit sollte ein Übergreifen der damals in Polen und der ČSSR verbreiteten Reformvorstellungen auf die DDR verhindert werden. “160

Als sich die politische Lage in Polen im Zeichen von Solidarnoš́ und Kriegsrecht erneut zuspitzte, wurde die Arbeit der Kommission noch weiter abgesichert - und gleichzeitig fachlich verflacht -, indem vor allem junge, politisch zuverlässige und mit Polen wenig verbundene Historiker mit begrenzten Sprachkenntnissen herangezogen wurden ${ }^{161}$. Häufiger als zuvor enthielten die Berichte ostdeutscher Kommissionsmitglieder über Begegnungen mit polnischen Kollegen nun

\footnotetext{
156 Heinrich Scheel, Zusätzliche Bemerkungen zu Punkt 5, als Anlage zum Beschlussprotokoll der Sitzung vom 10. Oktober 1958, Berlin, 10. 10. 1958, in: ABBAW, ZIG 710/1.

157 Heinrich Scheel, Bericht über die XVII. Tagung der Kommission der Historiker der DDR und der VR Polen in der Zeit vom 2. bis 5. Juni 1970 in Görlitz, 7. 7. 1970, in: ABBAW, ZIG 555 , Bl. 6.

158 „Dr. D. Lötzsch im DIZ wurde auf die Auseinandersetzung mit der, Ostforschung‘ umgesetzt, Dr. Kalisch, Rostock, als hauptamtlicher Gewerkschaftsfunktionär der Universität eingesetzt. Dr. Eva Seeber muss sich mit der Geschichte des sozialistischen Weltsystems nach 1945 beschäftigen. Dr. Lemke arbeitet an der Geschichte der UdSSR.“ Dadurch sei „die Beschäftigung mit der polnischen Geschichtswissenschaft in keinem Falle mehr institutionell gebunden, sondern ist sehr zufällig und mehr oder weniger für die die polnische Sprache beherrschenden Mitarbeiter eine Nebenbeschäftigung“. In: Ebenda.

159 Kommission der Historiker der DDR und der VR Polen, ohne Verfasserangabe, undatiert [1973 oder 1974], in: ABBAW, ZIG 171.

160 Behrendt, Osteuropahistoriographie in der DDR, in: Dahlmann (Hrsg.), Hundert Jahre Osteuropäische Geschichte, S. 187. Siehe auch Anm. 41.

161 Vgl. Rautenberg, Historikerkommission, in: Hellmann (Hrsg.), Osteuropa, Bd. 1, S. 122.
} 
auch ausführliche Schilderungen der politischen Lage im Nachbarland. So suchten am Rande der Tagung von 1981 „alle Mitglieder der [deutschen] Delegation die Gelegenheit zu persönlichen Gesprächen, bei denen in großem Umfang die gegenwärtige Lage in der VR Polen im Mittelpunkt stand. Dabei wurde die Gelegenheit genutzt, unseren Standpunkt in geeigneter Form darzulegen." ${ }^{162}$ Den polnischen Kollegen war umgekehrt bewusst, dass ihre Aussagen an die politischen Entscheidungsträger der DDR weitergereicht würden. Sie nutzten diesen informellen Weg bisweilen, um politische Botschaften an das befreundete sozialistische Ausland abzusetzen: „Übereinstimmend und fast beschwörend“ brachten sie etwa im selben Jahr zum Ausdruck, „die Bruderparteien mögen nicht die Geduld verlieren. Ein Einmarsch wäre die Katastrophe." Beinahe beleidigt musste Scheel konstatieren: „Keiner der Genossen zog als einen letzten Ausweg unsere Hilfe auch nur in Erwägung. “163

Schuld an der politisch-gesellschaftlichen Gärung im Nachbarland trugen aus Sicht der ostdeutschen Historiker nicht zuletzt die polnischen Fachkollegen hatten diese es doch immer wieder versäumt, ihre ideologische Vorbildfunktion in der Gesellschaft wahrzunehmen. Missbilligend stellte Olaf Groehler 1970 fest, dass „eine Reihe polnischer Historiker offenbar nur bedingt unsere Auffassung vom politischen Engagement der marxistischen Geschichtsschreibung“ teilt:

„Bezeichnend war in diesem Zusammenhang ein Gespräch mit Prof. Dr. Jedruszczak, Leiter des Militärhistorischen Instituts, der eine scharfe Trennung vom politisch-historischen Propagandisten, dessen Betätigungsfeld die Massenmedien im weitesten Sinne sind, und dem wissenschaftlich arbeitenden Historiker vornimmt. Bei dieser Diskussion betonte ich, dass die Arbeit des Historikers eine zutiefst politische Aufgabe ist und eine untrennbare Einheit zwischen der wissenschaftlichen und politisch-propagandistischen Tätigkeit des Historikers besteht. Als Beispiel für diesen Sachverhalt wurde auf die Haltung und die Tätigkeit der westdeutschen Historiker in den Massenmedien hingewiesen, die sich im Rahmen der Systemauseinandersetzung zwischen Kapitalismus und Sozialismus aller Mittel bedienen, um bürgerliche Ideologie zu verbreiten und es deshalb eine elementare Grundaufgabe jedes marxistischen Historikers sein müsse, auch der populärwissenschaftlichen Arbeit in den Massenmedien einen hervorragenden Platz einzuräumen, um sich nicht von der bürgerlichen Geschichtsschrei-

${ }^{162}$ Heinrich Scheel, Bericht über die Teilnahme an der XXVIII. turnusmäßigen Tagung der Historiker-Kommission der DDR und der VR Polen, 7. 7. 1981, in: ABBAW, ZIG 710/2.

${ }^{163}$ Heinrich Scheel, Bericht über Leitungsberatungen zwischen den Historikergesellschaften der DDR und der VR Polen im Rahmen der Vereinbarung über Freundschaft und Zusammenarbeit zwischen beiden Gesellschaften vom 2. Dezember 1974 in Warschau, VR Polen, Berlin, 1. 4. 1981, in: ABBAW, HG 160. 1986 hatte sich die Lage aus ostdeutscher Perspektive weiter verschlechtert - es war festzuhalten, „daß von den an der Tagung teilnehmenden 13 polnischen Historikern nach unserer Kenntnis nur einer Mitglied der PVAP war“. Regimekritische Äußerungen fielen inzwischen auch ,von polnischen Historikern, die zwar parteilos sind, in den Jahren 1980/81 aber einen politisch klaren, die Politik der ,Solidarność verurteilenden Standpunkt einnahmen“. Bericht über die XXXIII. Tagung der Historikerkommission DDR-VR Polen, ohne Verfasserangabe, undatiert [Ende Mai 1986], in: ABBAW, ZIG 710/2. 
bung in diesen Fragen in die Defensive drängen zu lassen [...] Prof. J. nahm meine Auffassungen zur Kenntnis und sagte, dass sie selbstverständlich Verständnis dafür hätten, wenn wir angesichts unserer Lage eine Reihe von Fragen politisch zugespitzter und schärfer in den Mittelpunkt stellten. Auch bei einzelnen Mitarbeitern (Getter) ist diese reservierte Haltung gegenüber den [sic.] aktiven politischen Engagement des Historikers zu beachten. ${ }^{\text {" }} 164$

In der hohen Politisierungsbereitschaft der ostdeutschen Historiker spiegelte sich ihre strikte Unterordnung unter die Staatsmacht. Deren Durchsetzungskraft ließ es geraten erscheinen, den Anforderungen von oben gerecht zu werden. Davon zeugt etwa der „Entwurf einer Konzeption über die internationale Arbeit auf dem Gebiet der Geschichtswissenschaft" aus dem Jahr 1966, der an der Staatsnähe der DDR-Historiographie keine Zweifel lässt:

„Die Auslandsarbeit der Historiker ist ein Teil der Außenpolitik der DDR überhaupt. Sie hat ihr zu dienen und muss sich in die kultur- und wissenschaftspolitische Konzeption der mit den außenpolitischen Aufgaben betrauten Institutionen in der DDR einfügen. “165

Dermaßen beflissen, der obrigkeitlichen Aufgabenstellung gerecht zu werden, verloren die ostdeutschen Geschichtsforscher allerdings zusehends die gesellschaftliche Nachfrage aus den Augen. Es war wohl nicht zuletzt der Seitenblick auf den polnischen Umgang mit Geschichte, der die ostdeutschen Historiker in den siebziger Jahren zur Einsicht gelangen ließ, dass der sozialistische Erziehungsauftrag am mangelnden Publikumsinteresse zu scheitern drohte. Besorgt konstatierte H. Meyer 1975 in der DPHK, es gebe eine "gewisse Diskrepanz zwischen dem Gegenstand, mit dem sich der Historiker beschäftigt, und dem, der den „Konsumenten historischen Wissens“ interessiere “166. Wie wir gesehen haben, begegnete die ostdeutsche Historiographie diesem Missstand Schulter an Schulter mit der Staatsführung, indem die historisch-nationale Selbstdefinition der DDR kontrolliert, aber umfassend erweitert wurde. Ob hierbei die polnische Geschichtspolitik Pate stand, bleibt eine offene Frage.

Außer Zweifel steht hingegen, dass sich dasselbe Problem in Polen ungleich zugespitzter präsentierte. Hier bedrängte eine zunehmend kritische Öffentlichkeit die immer defensiver agierenden Geschichtsideologen der Partei, wobei sich die Historiker in aller Regel als Vermittler zwischen staatspolitischen Vorgaben und gesellschaftlichen Bedürfnissen verstanden. Selbst ein Parteihistoriker wie Jarema Maciszewski forderte 1980 das Zentralkomitee der Polnischen Vereinigten Arbeiterpartei eindringlich auf:

\footnotetext{
164 Olaf Groehler, Reisebericht über Archivstudienreise in die Volksrepublik Polen vom 13. April bis zum 3. Mai 1970, undatiert, in: ABBAW, ZIG 171.

165 Entwurf einer Konzeption über die internationale Arbeit auf dem Gebiet der Geschichtswissenschaft, ohne Verfasserangabe, 29. 8. 1966, in: ABBAW, Arbeitsgemeinschaft der gesellschaftswissenschaftlichen Institute und Einrichtungen 72.

166 22. Konferenz der DPHK 1975 in Lublin, zit. nach Stelzig, Geschichtsbild, S. 275.
} 


\begin{abstract}
„[Es] ist stets Kontakt mit dem gesellschaftlichen Bewusstsein des Volkes zu halten. Wenn wir in unserer politischen Arbeit, auf dem Gebiet der Geschichte, entgegen dem gesellschaftlichen Bewusstsein handelten, dann würde zweifelsohne niemand uns hören und uns niemand glauben. Man darf z. B. keine Vorbehalte gegenüber der Zweiten Republik, gegenüber dem bürgerlich-jünkerlichen Polen haben, weil es überhaupt existierte, denn wenn wir bei einer Analyse der zwanzig Jahre zwischen den beiden Weltkriegen eine solche These aufstellen, dann würden sich die Menschen selbstverständlich von uns abwenden. Das sind theoretische Beispiele, denn solche Gedanken kommen wohl niemandem in den Sinn. Es wäre töricht, wenn wir z. B. Groll gegenüber den Soldaten des September [1939] hegten, weil sie in den Reihen einer bürgerlichen Armee kämpften, oder gegenüber den Teilnehmern am Warschauer Aufstand, weil sie überhaupt gekämpft haben." ${ }^{\text {167 }}$
\end{abstract}

Insgesamt wird man den polnischen Geschichtsforschern bescheinigen dürfen, dass sie der gesellschaftlichen Nachfrage seit den 1960er Jahren wesentlich weiter entgegenkamen als ihre ostdeutschen Kollegen, auf diesem Weg aber zumindest ein Stück weit von der offiziellen Geschichtspolitik begleitet wurden, sodass die Distanz zwischen Staat und Gesellschaft in zahlreichen Fragen geringer ausfiel als in der DDR.

Auf die deutsch-polnische Verständigung wirkte sich die beiderseitige Aufwertung nationaler Deutungsmuster derweil nicht unbedingt negativ aus. Zwar führte sie seit den siebziger Jahren zu einer schärferen Konturierung deutsch-polnischer Gegensätze, zwang aber gerade dadurch zur erneuten Beschäftigung mit ungelösten Kardinalfragen der gemeinsamen Beziehungsgeschichte - am deutlichsten in den bereits dargestellten Auseinandersetzungen um die preußische Geschichte. Hatte man eine „gemeinsame Sprache“ im sozialistischen Jargon nie ganz finden können, so schien sie jetzt in einer nationalbewussten Diktion möglich zu werden.

Das abrupte Ende der Kommission im Jahr 1990 kam für beide Seiten ebenso unerwartet wie die politische Wende, der es geschuldet war. Ehe sie sich versah, wurde die Geschichte im Dienste der Zukunft von der Gegenwart überrollt. Am 18. September 1990 traten leitende Kommissionsmitglieder in Warschau ein letztes Mal zusammen. Hier erklärte sich die deutsche Seite vor dem Hintergrund finanzieller und organisatorischer Unwägbarkeiten bis auf Weiteres außerstande, die Kommissionstätigkeit fortzuführen. Bezeichnend scheinen Gedanken zu einer - nicht verwirklichten - wissenschaftlichen Folgeinitiative, die sich in kontinuierlicher Form dem „Platz Deutschlands, Polens und Russlands in Europa“ widmen sollte. Dies darf wohl als Hinweis darauf verstanden werden, wie stark die Sowjetunion in der ostdeutsch-polnischen Kommission als abwesender Dritter doch stets mitgedacht worden war $^{168}$.

167 Übersetzung eines internen Vortrags von Prof. Jarema Maciszewski, Leiter Abt. Wissenschaft und Volksbildung im ZK [der PVAP], gehalten Mitte Juni 1980, in: ABBAW, ZIG 710/4.

168 Jan Kosim an Jan Zamojski, Warschau, 26. 9. 1990, in: APAN-W, III-308/6, Bl. 61-65. 


\section{Bilanzierende Thesen}

1. Die Auseinandersetzung mit der gemeinsamen Beziehungsgeschichte hinterlässt einen zwiespältigen Eindruck. Einerseits wurden im Rahmen der Kommission bisweilen durchaus kontroverse Themen aufgegriffen. Als Beispiele hierfür dürfen die Diskussionen um die Ursachen des Zweiten Weltkriegs und um PreuBens Rolle in der deutschen Geschichte gelten. Hier und in anderen Fällen wurden wiederholt auch sehr grundsätzliche Auseinandersetzungen ausgetragen, die weit über offiziell approbierte Geschichtsbilder hinauswiesen und etwa das heikle deutsch-polnisch-sowjetische Verhältnis im Umkreis des Hitler-Stalin-Pakts berührten. Angesichts solcher Tatsachen wäre es falsch, die Kommission einzig als Podium für den Austausch ritualisierter Bruderschaftsgesten zu verstehen. Wo dieser Eindruck entstand, war er der Praxis geschuldet, Auseinandersetzung hinter verschlossenen Türen auszutragen, erzielte Einigung hingegen öffentlich zu zelebrieren $^{169}$.

2. Andererseits ist nicht zu übersehen, dass die Kommission in strittigen Fragen nur bescheidene Verständigungserfolge verbuchen konnte. In der Regel verlegte man sich darauf, weitgehend unumstrittene und positiv konnotierte Gemeinplätze der deutsch-polnischen Beziehungsgeschichte in Erinnerung zu rufen, so etwa die deutsch-polnische Freundschaft im Völkerfrühling und in der sozialistischen Bewegung oder aber den gemeinsamen Gegner zu beschwören - Faschisten und Hakatisten in der Vergangenheit oder den „westdeutschen Imperialismus" in der Gegenwart. Wo substantielle Einigungen erzielt wurden, waren sie nicht der historiographischen Verständigung zwischen Deutschen und Polen, sondern dem politischen Schiedsspruch der Sowjetunion geschuldet. Deren geschichtsideologische Solidaritäten kamen bald den deutschen, bald den polnischen Interessen zugute und blockierten dabei oft die historisch berechtigten Interpretationen der jeweils anderen Partei. So stieß etwa das Interesse der DDRHistoriker an der deutschen Vergangenheit von Schlesien, Pommern und Ostpreußen auf die geschlossene Ablehnung von Polen und Russen; nach deren Willen waren die Oder-Neiße-Grenze und die Zwangsumsiedlungen als historische Notwendigkeiten zu legitimieren. Umgekehrt scheiterte die polnische Interpretation des September 1939 am gemeinsamen nationalbewussten Widerstand von DDR und UdSSR; eine ähnliche Komplizenschaft verband Deutsche und Russen auch hinsichtlich der polnischen Teilungen und der napoleonischen Kriege.

3. Ihre widersprüchlichen Sichtweisen stilisierten Polen und Deutsche zu einem methodischen Gegensatz. Unter dem Banner des historischen Materialismus vertraten ostdeutsche Historiker eine national nivellierende, sozial-stratifikatorisch

\footnotetext{
169 Am Rande sei bemerkt, dass dieser Umstand die politischen Risiken der fachwissenschaftlichen Diskussion zwar minderte, den ,volkspädagogischen“ Nutzen der Kommission - ganz im Gegensatz zur westdeutsch-polnischen Schulbuchkommission, die stets auch von der öffentlichen Diskussion ihrer Arbeit lebte - aber gegen Null tendieren ließ. Den ausgeprägten antipolnischen Vorurteilen in der DDR-Bevölkerung dürfte die Kommission somit kaum entgegengewirkt haben.
} 
akzentuierte Sichtweise der deutsch-polnischen Beziehungen (Zwei-Linien-Paradigma), während ihre polnischen Kollegen weiterhin mehrheitlich aus der Warte einer traditionellen Nationalgeschichte argumentierten.

4. Im Rahmen dieser gegensätzlichen Geschichtsbilder folgte der ostdeutsch-polnische Dialog bald eingespielten Diskursmustern: Die DDR-Historiker strebten danach, sich vom negativen Strang der deutschen Geschichte zu distanzieren und ihn der reaktionären Monopolbourgeoisie anzulasten, die 1949 in einem ebenso reaktionären Staat - der Bundesrepublik - aufgegangen sei, und den positiven Strang der deutschen Geschichte herauszuarbeiten, ihn mit den „progressiven "Klassenkräften - insbesondere dem Proletariat - zu identifizieren und als Vorgeschichte der DDR zu vereinnahmen. Gegenüber der nationalsozialistischen Vergangenheit verstanden sich die DDR-Historiker daher weniger als Angehörige einer reuigen Nation denn als anklagende Klasse. Dabei war ihnen auch daran gelegen, den Polen bei ihrer Geschichtsdeutung dieselbe Zweispurigkeit von progressiver und reaktionärer Traditionslinie nahezubringen und so auf eine normative Gleichstellung Polens und Deutschlands hinzuwirken. Bezüglich des deutsch-polnischen Verhältnisses ging es schließlich darum, Verknüpfungen zwischen den positiven Linien beider Nationalgeschichten aufzuzeigen, aber auch eine Vergleichbarkeit der negativen Linien herauszuarbeiten (tu-quoque-Argument).

5. Demgegenüber drängten die polnischen Historiker darauf, die polnische Geschichte in ihrer Gesamtheit als überwiegend positiven Entwicklungsstrang darzustellen, wobei kaum nach Klassen unterschieden wurde. Kritikwürdige Aspekte der polnischen Geschichte wurden demzufolge ausgeblendet - wie im Falle der Zwangsaussiedlung der deutschen Bevölkerung - oder allenfalls als vereinzelte dunkle Flecken zugelassen, eine kohärent negative („reaktionäre“) Tradition der polnischen Nationalgeschichte wurde aber entschieden verneint. Bezüglich des deutsch-polnischen Verhältnisses wurde ein normatives Gefälle zugunsten Polens betont; hinsichtlich der Gegenseite plädierten die Polen auf Unteilbarkeit nationaler historischer Verantwortung. Dahinter stand die Überzeugung, dass strittige Fragen nicht zu lösen seien mit einer Partei, die sich ausschließlich als Verkörperung des „Guten“ in der deutschen Geschichte verstand. Dieser Umstand erklärt vielleicht mehr als jeder andere Faktor das polnische Interesse an der Schulbuchkommission mit der Bundesrepublik, oder - besser noch - an dreiseitigen polnisch-doppeldeutschen Geschichtsgesprächen, die von der DDR indes konsequent verweigert wurden.

6. Aus dem Gesagten geht bereits hervor, dass die Kommission den nationalen Gegensatz mitnichten ausräumen konnte. Mochte auch die sozialistische Meistererzählung vom internationalen Klassenkampf die nationalen Narrative bisweilen überdecken - überwinden konnte sie sie keinesfalls. Das möglicherweise vorhandene Potential einer gesellschaftsgeschichtlichen Betrachtungsweise, allzu nationalistische Perspektiven aufzubrechen, machte die ostdeutsche Seite zunichte, indem sie einen dogmatischen historischen Materialismus benutzte, um zu einer Gleichwertung von polnischer und deutscher Geschichte zu gelangen. Es erstaunt kaum, dass diese Sichtweise der gemeinsamen Beziehungsgeschichte in Polen 
kaum Anhänger gewinnen konnte, solange sie als Vehikel einer apologetischen Geschichtsklitterung diente.

7. So ist das sozialistische Geschichtsbild, dessen konsensstiftende Wirkung immer wieder betont wurde, in Wahrheit eher als Hemmschuh der deutsch-polnischen Verständigung zu werten. Pointiert ließe sich gar behaupten, dass erst die in den späten sechziger Jahren beginnende Wiederaneignung der Nationalgeschichte durch die DDR-Historiographie beide Seiten allmählich zu einer gemeinsamen Sprache zurückfinden ließ. Jedenfalls lassen die polnischen Reaktionen auf den erweiterten Erbe-Begriff nebst anfänglicher Besorgnis auch eine gewisse Erleichterung darüber erkennen, dass die DDR-Historiographie ihre nationalen Positionen nun wieder unverstellt vortrage. Auf dieser Basis konnte sich die DPHK daran machen, strittige Fragen wie die Bewertung Preußens oder die Beurteilung des Zweiten Weltkriegs neu auszuhandeln. Auf polnischer Seite wurde dabei durchaus erkannt, dass die DDR-Historiker auf ihren Reakquirierungszügen durch die deutsche Vergangenheit auch zunehmend ambivalente Erbstücke für sich reklamierten und sich in der Folge nicht mehr so einfach aus der Verantwortung für die negativen Erscheinungen der deutschen Geschichte würden stehlen können. Auf die daraus erwachsenden Widersprüche wurde in steigender Kadenz hingewiesen.

8. Außer Frage steht, dass die Historikerkommission in den siebziger Jahren vom westdeutsch-polnischen Dialog überholt wurde. Immerhin dürfte die Auseinandersetzung mit den ostdeutschen Kollegen die polnischen Geschichtsforscher in gewissem Sinne auf ihre späteren Gespräche mit den bundesdeutschen Historikern vorbereitet haben. Letztlich verdeutlicht der Vergleich mit der Schulbuchkommission aber vor allem, dass die deutsch-polnische Geschichtsverständigung im staatssozialistischen Kontext weniger an nationalen Gegensätzen scheiterte so schwerwiegend diese auch sein mochten - als vielmehr an gänzlich verschiedenen Auffassungen von den politischen Aufgaben, Möglichkeiten und Grenzen der Historiographie. 